\title{
Transcriptional Dissection of Human Limbal Niche Compartments by Massive Parallel Sequencing
}

\author{
Chris Bath ${ }^{1,2}$, Danson Muttuvelu ${ }^{1}$, Jeppe Emmersen ${ }^{2}$, Henrik Vorum ${ }^{1}$, Jesper Hjortdal ${ }^{3}$, Vladimir Zachar $^{2 *}$ \\ 1 Department of Ophthalmology, Aalborg University Hospital, Aalborg, Denmark, 2 Laboratory for Stem Cell Research, Aalborg University, Aalborg, Denmark, \\ 3 Department of Ophthalmology, Aarhus University Hospital, Aarhus, Denmark
}

\begin{abstract}
Corneal epithelium is maintained throughout life by well-orchestrated proliferation of limbal epithelial stem cells (LESCs), followed by migration and maturation centripetally towards the ocular surface. Disturbance of LESCs can potentially lead to a blinding condition, which can be reversed by reconstitution of a functional LESC pool. The current clinical procedures are effective to some degree, however, deeper knowledge of the molecular interplay within the limbal niche is necessary to achieve a fully satisfactory patient outcome. The present study was thus undertaken to carry out a comprehensive transcriptome analysis of four distinct human limbal compartments, including basal limbal crypts (BLCs), superficial limbal crypts (SLCs), cornea, and the supporting stroma, with the aid of laser capture microdissection and deep RNA sequencing. The tissue harvest pipeline was rigorously optimized so that the exposure to cold ischemia would be less than five minutes. The global gene ontology analysis confirmed existence of primitive cells in BLCs, migratory and activated cells in SLCs, and differentiated cells in cornea. Interestingly, many significantly upregulated genes in SLCs mapped to processes involved in regulation of vasculature, such as SFLT1. In contrast, BLCs exhibited many genes mapping to neurogenic processes and processes related to cell development. The primitive nature of BLCs was, furthermore, confirmed by the KEGG pathway analysis, and some potential regulators of LESCs were revealed, such as Lrig1 and SOX9. The analysis also yielded comprehensive lists of uniquely expressed genes in both BLCs and cornea, which may be useful to identify possible biomarkers. In conclusion, the current investigation provides new insight into the relationship between distinct cell populations within the limbal niche, identifies candidates to be verified for novel biological functions, and yields a wealth of information for prospective data mining.
\end{abstract}

Citation: Bath C, Muttuvelu D, Emmersen J, Vorum H, Hjortdal J, et al. (2013) Transcriptional Dissection of Human Limbal Niche Compartments by Massive Parallel Sequencing. PLoS ONE 8(5): e64244. doi:10.1371/journal.pone.0064244

Editor: Irina Kerkis, Instituto Butantan, Brazil

Received February 9, 2013; Accepted April 10, 2013; Published May 22, 2013

Copyright: (C) 2013 Bath et al. This is an open-access article distributed under the terms of the Creative Commons Attribution License, which permits unrestricted use, distribution, and reproduction in any medium, provided the original author and source are credited.

Funding: This study was supported by grants from The Danish Eye Foundation, Aalborg University Hospital, the John and Birthe Meyer, Jochum Jensen \& hustru Mette Marie Jensen f. Poulsen, Marie Jensen, and Heinrich Kopps foundations. The funders had no role in study design, data collection and analysis, decision to publish, or preparation of the manuscript.

Competing Interests: The authors have declared that no competing interests exist.

*E-mail: vlaz@hst.aau.dk

\section{Introduction}

Regenerative medicine is a rapidly developing field promising to cure intractable diseases by adopting both tissue engineering and cell transplantation-based strategies. One of the most successful clinical procedures has been cultured limbal epithelial transplantation (CLET), where the corneal epithelium, damaged due to stem cell dysfunction or depletion, can be repaired using ex vivo engineered stem cell grafts. The outcome of surgery is dependent on the graft sheet quality, and thereby the ex vivo expansion protocols. The basic culturing approach implemented for CLET [1] was originally developed using epidermal keratinocytes [2,3]. Significant effort has since been expended to optimize the ex vivo propagation of LESCs with the ultimate goal of increasing success rates of the transplantation procedures [4-14]. These attempts have been complicated by the lack of stem cell markers and the precise knowledge of molecular regulations involved in the homeostasis of the limbal niche [15].

Corneal epithelium is composed of a multilayered nonkeratinized squamous epithelium. Since the early study by Mann (1944) [16], convincing evidence has accumulated to identify corneal limbus as the stem cell reservoir for the continuous replenishment of corneal epithelial cells throughout the lifetime of an individual [17-23]. The stem cells are thought to be located in distinct stem cell niches deep in the epithelium specialized in maintaining stem cells, a concept first described by Schofield for the hematopoietic system [24]. In the cornea, these histologically defined structures are termed limbal crypts [23], limbal epithelial crypts [25], or focal stromal projections [23]. Studies have shown, that the limbal epithelial stem cells (LESCs) differentiate as they move away from the basal crypts towards the central cornea, where they migrate superficially, and are ultimately lost to the external environment [18].

Most molecular biological techniques require the desired cell population to be isolated from the surrounding tissue prior to analysis. This has traditionally been performed using either mechanical or enzymatic dissociation with an almost certain change in expression profiles [26-28] but also a risk of contamination. A technique, whereby these obstacles can be circumvented, is the use of laser capture microdissection (LCM) [26], which allows separation based on morphological criteria of specific subpopulations from their complex biological environment. LCM is especially suitable for the isolation of corneal 
epithelial subpopulations due to their unique spatial organization along the differentiation pathway.

A low frequency of stem cells in a given tissue is another problem, frequently associated with stem cell research. The signals from a few stem cells are inevitably lost in the larger pool of mixed cell populations and even after enrichment by LCM, the RNA yield may be too low to allow for global transcriptional profiling using traditional microarrays [29]. The more sensitive massive parallel sequencing thereby provides an optimal tool for investigating complex eukaryotic transcriptomes from sparse stem cell populations. Advantages over traditional microarrays include less bias, lower false positive signals, higher reproducibility, an almost unlimited dynamic range, and a very high sensitivity [29-31]. A considerable benefit is also the possibility to identify novel genes and alternative transcripts. Deep RNA sequencing thus lends itself as a method of choice to analyze limited amount of source material such as that from specific limbal compartments.

In the current investigation, we present comprehensive sequence data from the transcriptomes of discrete differentiation stages of corneal epithelium and supporting stroma using a powerful combination of laser capture microdissection and RNA sequencing. In addition to new evidence about molecular networks associated with the limbal niche, the investigation provided an abundance of information for prospective data mining.

\section{Materials and Methods}

\section{Tissue Acquisition and Processing}

The study was approved by The North Denmark Region Committee on Health Research Ethics, and a written informed consent was obtained prior to inclusion. The inclusion criteria stipulated, that the donor should be older than 18 years of age with no history of mental illness. The exclusion criteria specified the absence of both prior radiation therapy against ocular surface, diseases at the ocular surface, and systemic inflammatory diseases. An otherwise normal human eye suffering from malignant melanoma of the retinal pigment epithelium layer was procured, and the corneo-limbal region was isolated and processed immediately after enucleation at the operation theatre to preserve the integrity of material. During all steps along the RNA isolation procedure, only RNase-free reagents were used, the work was restricted to a designated area, surfaces were treated with RNase AWAY (VWR-Bie \& Berntsen, Herlev, DK), and a protective clothing was worn. The corneo-limbal tissue was divided by three parallel cuts, each $4 \mathrm{~mm}$ apart, into four strips using a custommade corneal cutting device. The tissue was then stabilized with Tissue-Tek OCT (Sakura Finetek Europe, Alphen aan den Rijn, The Netherlands) inside cryomolds and flash-frozen in a mixture of isopenthane and dry ice. The samples were transported to the laboratory on dry ice, and stored at $-140^{\circ} \mathrm{C}$ until further use.

The tissue blocks were processed into $10 \mu \mathrm{m}$ serial sections using an HM $505 \mathrm{~N}$ cryostat (Microm International, Germany) and mounted on Superfrost Plus glass slides (Thermo Fisher Scientific, Waltham, MA) for phase contrast inspection of niche structures. The selected sections were then transferred onto UV irradiated $\left(3000 \mu \mathrm{J} / \mathrm{cm}^{2}\right)$ PEN (polyethylene naphtalate)-membrane metal-framed slides (Life Technologies, Naerum, Denmark), and fixed in $70 \%$ ethanol at $-30^{\circ} \mathrm{C}$ for $2 \mathrm{~min}$. The staining procedure was completed inside a laminar flow bench using RNase-free pap-jars (Evergreen Scientific, Los Angeles, CA) and reagents pre-cooled to $4^{\circ} \mathrm{C}$. In short, the slides were washed with water, counter-stained with $0.01 \%$ cresyl violet for $10 \mathrm{sec}$, and washed with $70 \%$ ethanol for 30 sec. Finally, the preparations were dehydrated with $100 \%$ ethanol for $2 \mathrm{~min}$ and xylene for
5 min. The slides were kept inside the pap-jars at room temperature to avoid condensation of water, which could activate endogenous RNases and interfere with LCM.

\section{Laser Capture Microdissection and RNA Isolation}

The stained tissue sections were sandwiched with Superfrost Plus glass slides to provide a support for dissection and capture in a Veritas microdissection instrument (model 704; Arcturus Bioscience, Mountain View, CA), which was equipped with IR capture and UV cutting lasers. The particular arrangement of the specimen (inverse technique) offered distinctive benefits in minimizing the risk of contamination and enabling both large capture area and constant laser settings. The efficiency of capture thus attained $100 \%$, and the hands-on time to finalize the procedure was reduced greatly. The settings for IR laser pulse were power $100 \mathrm{~mW}$, duration $2.7 \mathrm{msec}$, and hit frequency 1 . The UV laser was set on a constant low power. Four discrete compartments were targeted, the basal limbal crypts (BLCs), the superficial limbal crypts (SLCs), the paracentral/central corneal epithelium, and the adjacent limbal stroma. Each of the four specific areas from a single tissue cryosection was comprehensively sampled and collected on individual CapSure Macro LCM Caps (Life Technologies). A single capture cap was used for up to three cryosections and altogether 15 cryosections were processed. To keep the exposure to less than 1 hour, only three specimens were handled at a time, and upon completion, the thermoplastic film overlaid samples were immediately stripped from the caps to be used for RNA extraction.

The total RNA was isolated using PicoPure RNA isolation kit (Life Technologies) according to the manufacturers protocol, including an additional step of DNase I treatment (Sigma-Aldrich, St. Louis, MO), and stored at $-140^{\circ} \mathrm{C}$ until use. The integrity and concentration was determined in the Agilent Bioanalyzer 2100 (Agilent Technologies, Santa Clara, CA) using the Agilent RNA 6000 Pico Kit (Agilent Technologies).

\section{RNA Amplification and Sequencing}

The total RNA was reverse-transcribed and amplified using Ovation RNA-Seq System V2 kit (NuGEN Technologies, San Carlos, CA), and after quantification of dsDNA by the Qubit kit (Life Technologies), the libraries were constructed for paired-end sequencing with the aid of a TruSeq DNA Sample Preparation Kit (Illumina, San Diego, CA). The libraries were quantified by a realtime PCR and further purified employing Agencourt AMPure XP beads (Beckman Coulter, Brea, CA). Finally, to assure optimal loading for cluster generation, the extracted libraries were quantified using a KAPA Library Quant Kit (KAPA Biosystems, Woburn, MA). Sequencing was performed on the Illumina HiSeq2000 platform (Illumina). The sequences were submitted to ENA (European Nucleotide Archive) under accession number E-MTAB-1498.

\section{Reads Assembly and in silico Gene Expression Analysis}

The sequencing data were imported as paired-ends into CLC Genomics Workbench 5.5.1 (CLC bio, Aarhus, Denmark) for downstream processing and analysis. Initial trimming of reads was performed using a maximal allowed ambiguity number of 2 within reads, 0.05 limit on quality score, and a removal of the initial ten 5' base pairs. Assembly of reads was performed against an annotated Homo sapiens hg19 reference genome and followed by a creation of 4 distinct RNA-sequencing experiments, the stroma vs. BLCs, the BLGs vs. SLCs, the SLCs vs. cornea, and the BLCs vs. cornea. Venny (Oliveros, J.C. (2007) VENNY. An interactive tool for comparing lists with Venn Diagrams. http://bioinfogp. 
cnb.csic.es/tools/venny/index.html) was used to render 4-way interactions among the independent libraries according to selected criteria, and Gene-E (http://www.broadinstitute.org/cancer/ software/GENE-E/) was invoked to produce heat maps of RPKM values based on hierarchical clustering.

\section{Hypergeometric Testing on Annotations and Gene Ontology (GO) Visualization}

Hypergeometric tests were performed on annotations using updated databases from The Gene Ontology for GO categories from Biological Process and Kyoto Encyclopedia of Genes and Genomes for pathways in ClueGO [32]. Only genes with FDR corrected p (q) $\leq 0.05$ and a fold-regulation $>2$ in a pairwise compartment comparison were included in the hypergeometric testing. The ClueGO output was restricted to GO categories with $\mathrm{q} \leq 0.05$, and the GO term fusion was used to avoid redundancy prior to visualization of networks in the Cytoscape environment [33]. Grouping of terms was based on kappa statistics, and the leading term was highlighted in the networks in italics. For the global analyses of epithelial populations only GO levels from 1 to 10 were allowed, with at least 5 genes per node and a minimal representation of $3 \%$ genes for each term. Specific gene lists for global terms were then remapped in a more detailed analysis. No filtering was performed, when significant genes were mapped to the Kyoto Encyclopedia of Genes and Genomes (KEGG) pathways. GraphPad Prism software (GraphPad Software, La Jolla, CA) was used to create the bar charts.

\section{Statistics}

Significance was tested using proportional statistics on total exon reads using method by Kal et al. (1999) [34] as implemented in the CLG software. Stringent criteria were applied, involving q $\leq 0.05$ according to Benjamini and Hochberg [35], fold-regulation $>2$ for estimation of up- and downregulated transcripts, and also q $\leq 0.05$ for estimation of significant GO categories. The criteria for potential candidate stem cell and differentiation markers in the BLCs and cornea, respectively, stipulated that the detected transcripts must be unique to the tissue, $\mathrm{q} \leq 0.05$, and RPKM higher than that of the SLGs used for comparison.

\section{Results}

\section{Preparation and Evaluation of Compartment-specific Libraries}

The spatial arrangement of epithelial subpopulations on the ocular surface allowed for capturing of discrete cellular compartments along the differentiation pathway from BLCs to the superficial cornea. In addition, supporting stroma to this epithelium was successfully retrieved. Representative images of the laser capture procedure along with an electropherogram illustrating integrity of the isolated RNA are shown in figure 1A. The quality of RNA, as expressed by the RIN number, was around six, and the amount of total RNA surpassed $5000 \mathrm{pg}$ in all pooled samples.

The sequencing of the BLC, SLC, cornea, and stroma libraries produced $92,711,354,85,584,998,106,506,532$, and 86,574,660 paired reads, respectively. Only one third of the reads was found to map to exons (Table S1), which resulted in correspondingly low reads per kilobase per million mapped reads (RPKM) values. This was due to the amplification procedure that employed random SPIA primers. Average read length after trimming the initial 101 bp reads was 86.5 for BLCs, 85.9 for SLCs, 86.2 for cornea, and 86 for stroma. The mapping was performed against 55,075 genes and 162,508 transcripts from Homo sapiens hyl9 genome.

\section{Relatedness and Distribution of Transcriptional Expression between Limbal Compartments}

The samples appeared to cluster according to expectations in the principal component analysis, demonstrating relatedness of the epithelial populations away from the stroma (Fig. 1B, left panel). This was further corroborated by hierarchical clustering and scatter plots (data not shown). The volcano plots were symmetrically distributed around 0 , and many transcripts were both significantly and differentially expressed between compartments (Fig. 1B, right panel).

Mapping to the Homo sapiens genome (hg19) revealed 16,125 genes expressed in BLGs, 14,847 in SLGs, 16,208 in cornea, and 12,451 in the stroma. The analysis of gene distribution by a fourway Venn diagram plotting indicated that the majority of transcripts were shared, although a limited number of uniquely expressed genes were confirmed as well (Fig. 1C, left panel). After filtering for genes with $\mathrm{q} \leq 0.05$ and a fold-change $>2$, as expected, the corneal subpopulations appeared more disparate (Fig. 1C, middle panel). However, the most accurate information about the prevalence of rare unique transcripts, that potentially may prove to represent novel biomarkers, was obtained after filtering unique genes with $\mathrm{q} \leq 0.05$ (Fig. $1 \mathrm{C}$, right panel). The distribution analysis thus confirms, that all compartments have a specific transcriptional signature, and each of them features a set of uniquely expressed genes.

The RPKM is a normalized measure of expression levels in RNA sequencing. Genes with $q \leq 0.05$ and a fold-change $>2$ were grouped based on RPKM values using the method of hierarchical clustering, and a global heatmap was compiled (Fig. 2). It is clearly evident that distinct subpopulations of corneal cells use specific transcriptional programs that reflect their functional differences.

\section{GO Analysis of Differentially Expressed Genes in BLCs}

The association between compartment-specific transcriptional activity and cellular function was examined using Gene Ontology. The analysis was based on statistical significant overrepresentation of categories in the ontology Biological Process. The GO analysis for BLCs revealed the presence of functions indicative of development and differentiation within the corneal context (Fig. 3). This is evident from the fact, that the term Cell Development was identified as a group leading term. The genes mapping to this leading term were also remapped in more detail and are available as supplemental information (Fig. S1). In particular, it was possible to identify several processes central to development, such as Epithelial to Mesenchymal Transition, Mesenchymal Cell Development, Mesenchymal Cell Differentiation, and Regulation of Cell Morphogenesis Involved in Differentiation. From the point of limbal homeostasis it appears important, that the category Pigmentation was significantly enriched. The presence of melanocytes in corneal epithelium is restricted to BLCs, where they are presumed to protect the LESCs from UV-induced damage [36]. A more detailed mapping of Pigmentation also confirmed the ocular nature of pigmentation as Eye Pigmentation.

The prominent attribute of BLCs as a location harboring the LESGs was further substantiated by finding the presumed stem cell markers upregulated and the differentiation markers downregulated when compared with the other compartments. Thus the RPKM values for Homo sapiens tumor protein p63 (transcript variant 4), also known as deltaNp63 $\alpha$, were 16.34 in the BLCs, but 11.94 and 10.42 in the SLCs and cornea, respectively. Similarly, for cytokeratin 19 (KRT19), the values were 47.62 and 62.42 in the BLCs and SLCs, respectively, but only 24.32 in the cornea. Very low expression values for ABCG2 were observed in all compartments, but expression of a family member ABCC4 was 
A
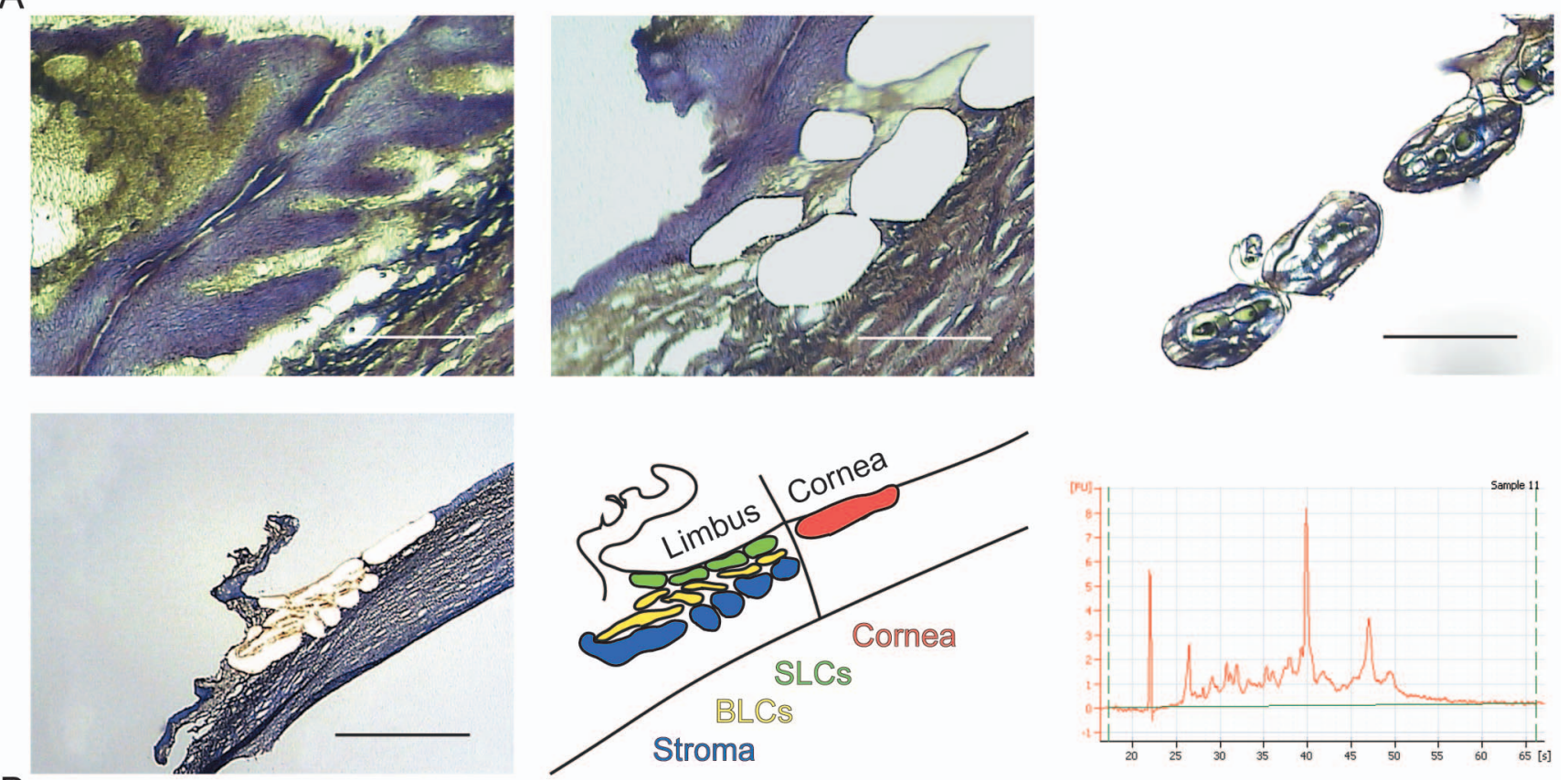

B
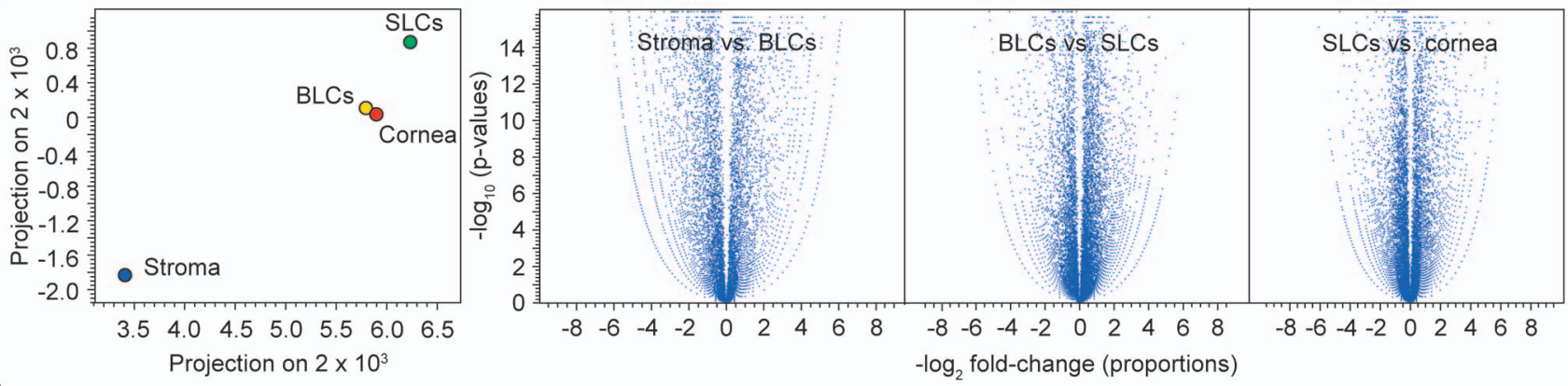

C

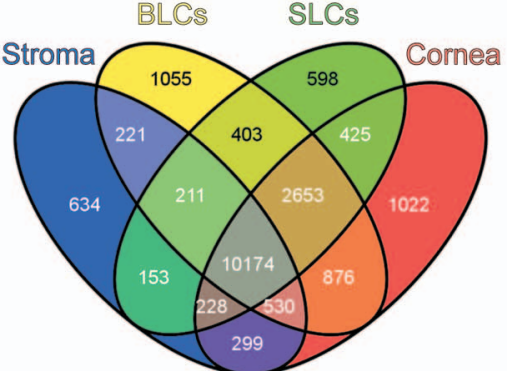

Detected genes

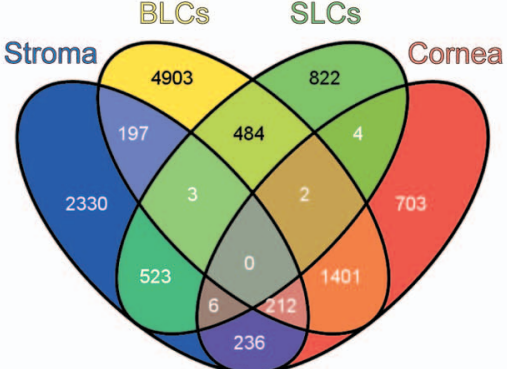

Genes with FDR $<0.05$ and fold-change $>2$

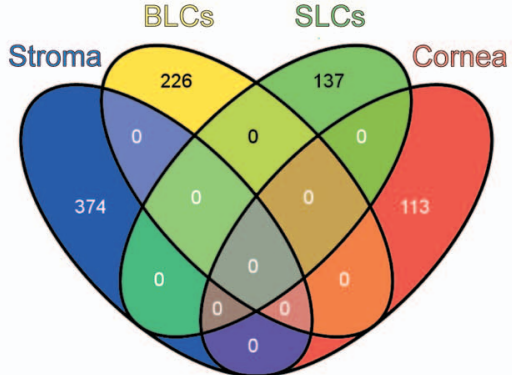

Unique genes with FDR $<0.05$

Figure 1. LCM of the corneal limbus and comparison of the compartment-specific libraries. (A) Representative images from the LCM procedure and the electropherogram of the isolated RNA. Scale bars high power magnification, $200 \mu \mathrm{m}$; low power magnification, $1 \mathrm{~mm}$. (B) Principal component analysis and volcano plots of the compartment-specific libraries. (C) Distribution of transcriptional expression between limbal compartments using four-way Venn Diagrams.

doi:10.1371/journal.pone.0064244.g001

found uniquely in BLGs. As already mentioned, the expression pattern of the differentiation markers was inversely related to that of stemness-associated markers. Thus for cytokeratin 3 (KRT3), the values were 14.32 in the BLCs, increasing to 37.37 and 32.28 in the SLCs and cornea, respectively, and likewise for connexin 43 (GJA1), the values were growing from 133.74 in the BLCs to 182.76 and 230.34 in the SLCs and cornea, respectively.
GO Analysis of Differentially Expressed Genes in SLCs

The significant GO terms for SLCs are presented in figure 4. The SLGs are known to harbor transient accelerating cells (TACs), which are differentiating as they migrate towards the superficial central cornea. In line with the known function of this compartment to support migratory cells, we found significant GO terms for Cell Migration and Locomotion. The fact that TACs are known to differentiate and develop into mature corneal epithelium 


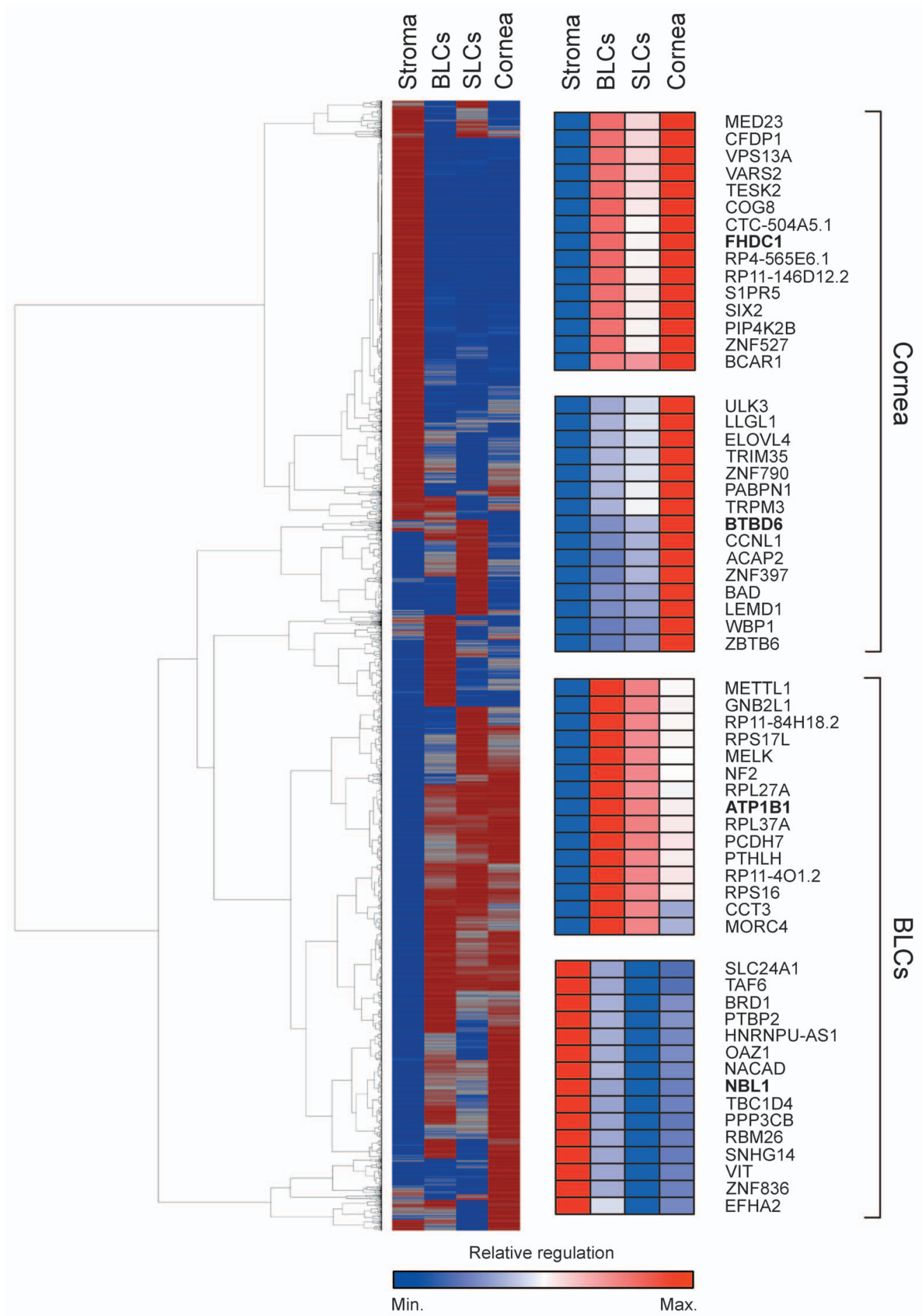

Figure 2. Heatmap of significantly expressed genes in BLCs, SLCs, cornea, and stroma after hierarchical clustering based on RPKM values. Red indicates high, and blue low RPKM. High resolution inserts for FHDC1 and BTBD6, and ATPB1 and NBL1 are presented. doi:10.1371/journal.pone.0064244.g002

during this migration was reflected in the GO terms Epithelial Cell Differentiation, Anatomical Structure Development, and Cell Activation. An especially interesting finding of this analysis was the significant enrichment for terms involved in control of angiogenesis.

\section{Comparative BLC and SLC Pathway and GO Analyses}

As evident from the comparative GO analysis, the BLCs were relatively enriched in terms related to developmental processes, synapse assembly, synapse organization, and adhesion, while SLCs were enriched for terms essentially related to vasculature (Fig. 5). The genes that were found significantly upregulated $(\geq 2$-fold, $q$ $\leq 0.05)$ in the BLCs with respect to SLCs, were also mapped to 
A

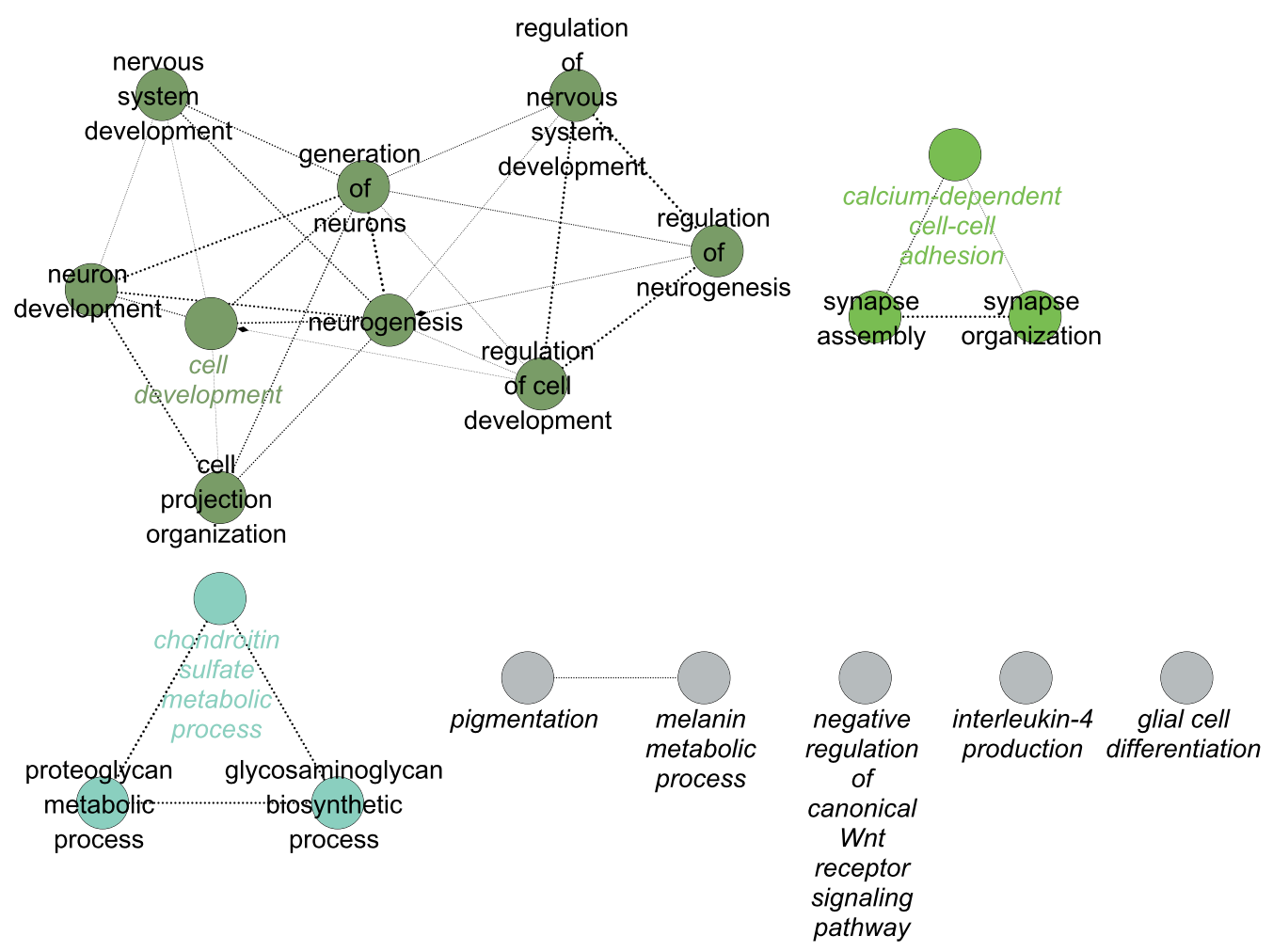

B

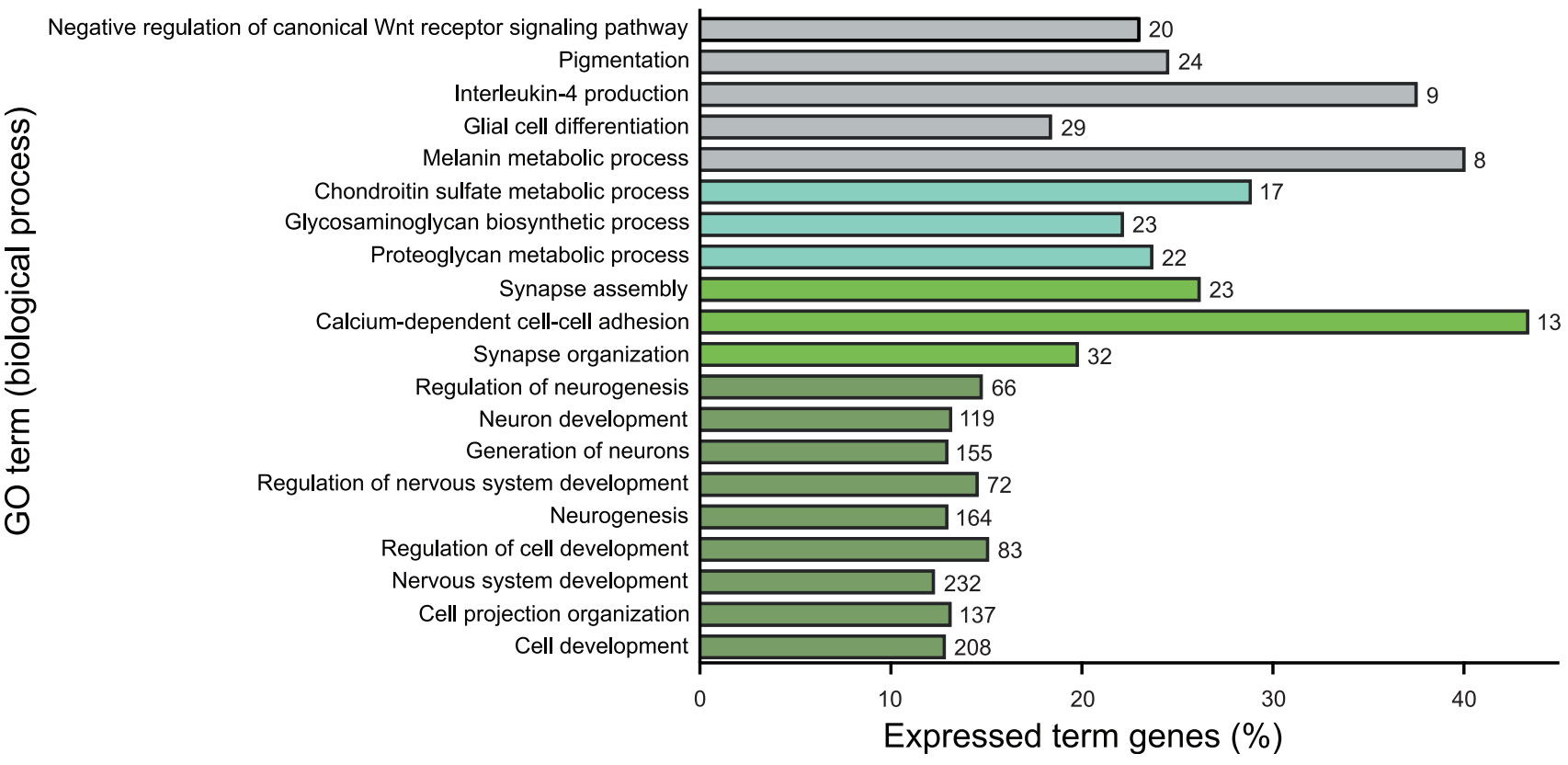

Figure 3. Gene ontology analysis of significantly upregulated genes in BLCs. (A) Network of significantly enriched terms. (B) Bar chart of significantly enriched terms. Numbers next to the bars indicate total number of genes mapping to the specific term. doi:10.1371/journal.pone.0064244.g003

known pathways according to KEGG. Many pathways involve the signaling and cancer-associated pathways, thus emphasizing the primitive nature of BLGs. These pathways, including their corresponding lists of mapped genes, are included in the supporting material (Table S2).
GO Analysis of Differentially Expressed Genes in Cornea

The differentiated post mitotic (PMCs) and terminally differentiated cells (TDCs) are located in paracentral/central cornea together with some late TACs. Figure 6 represents a global GO analysis of significantly enriched terms in the cornea. As expected, the biological processes in this group are of a more differentiated 
A

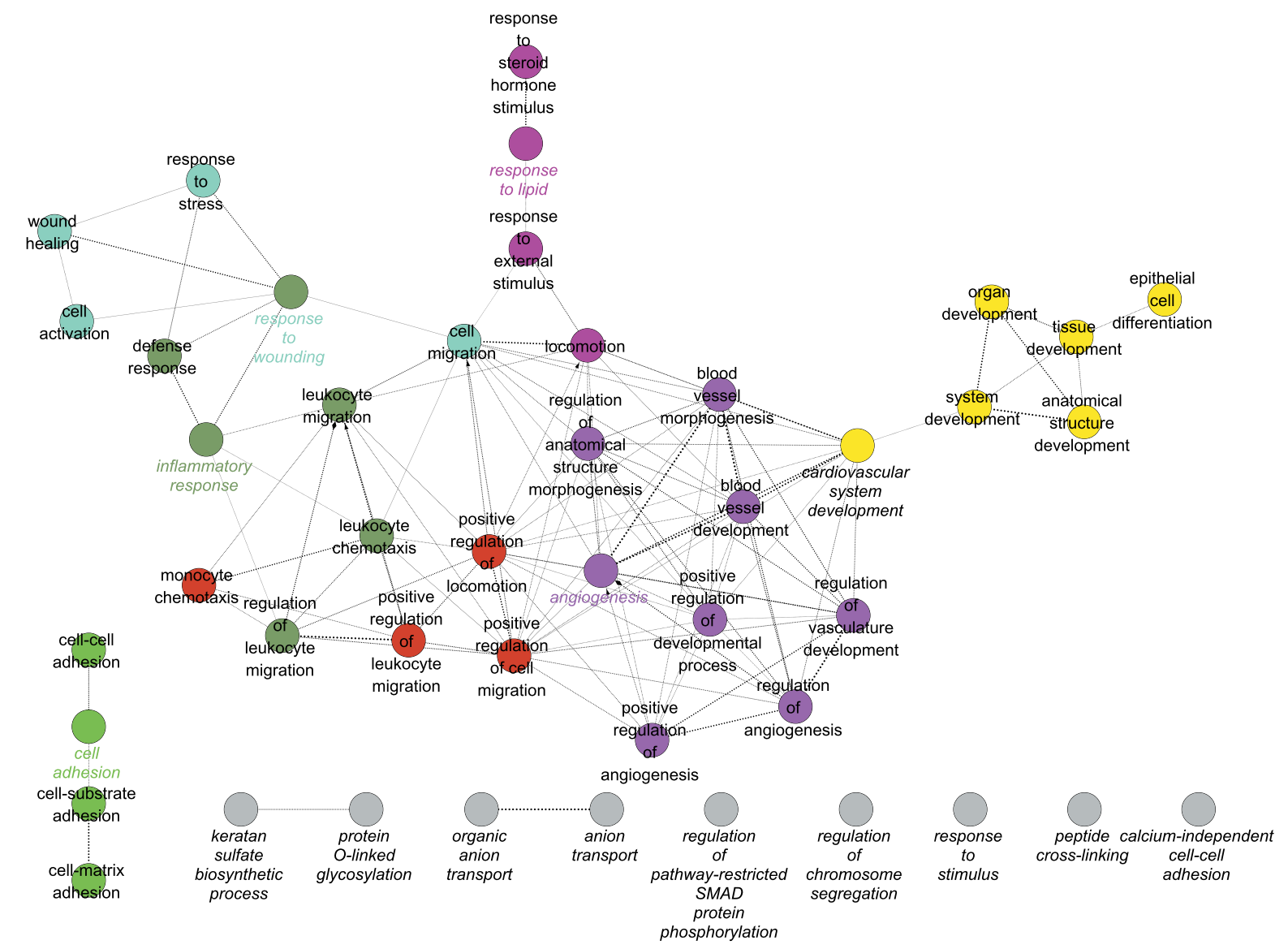

B

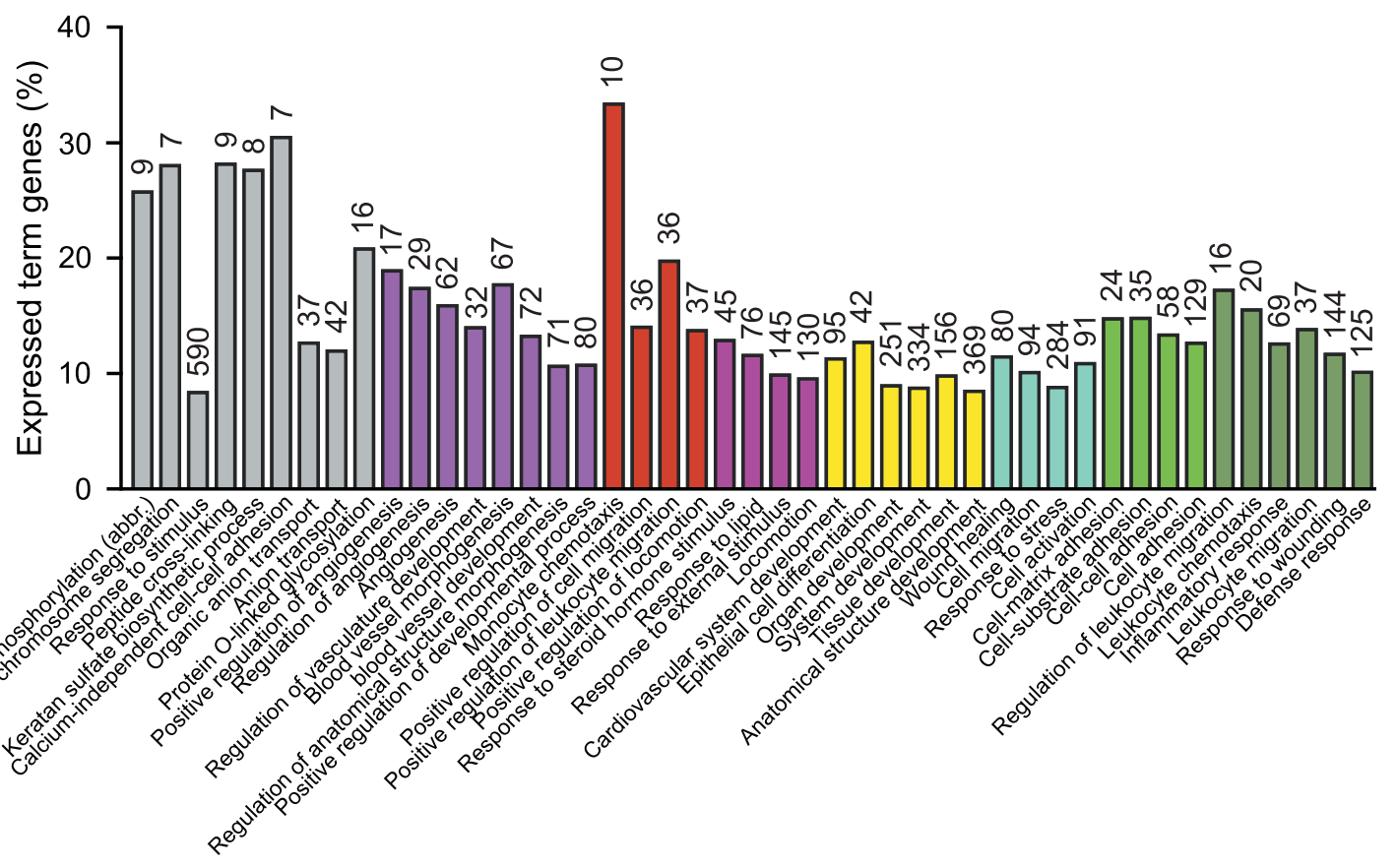

GO term (biological process)

Figure 4. Gene ontology analysis of significantly upregulated genes in SLCs. (A) Network of significantly enriched terms. (B) Bar chart of significantly enriched terms. Numbers next to the bars indicate total number of genes mapping to the specific term. doi:10.1371/journal.pone.0064244.g004 
A
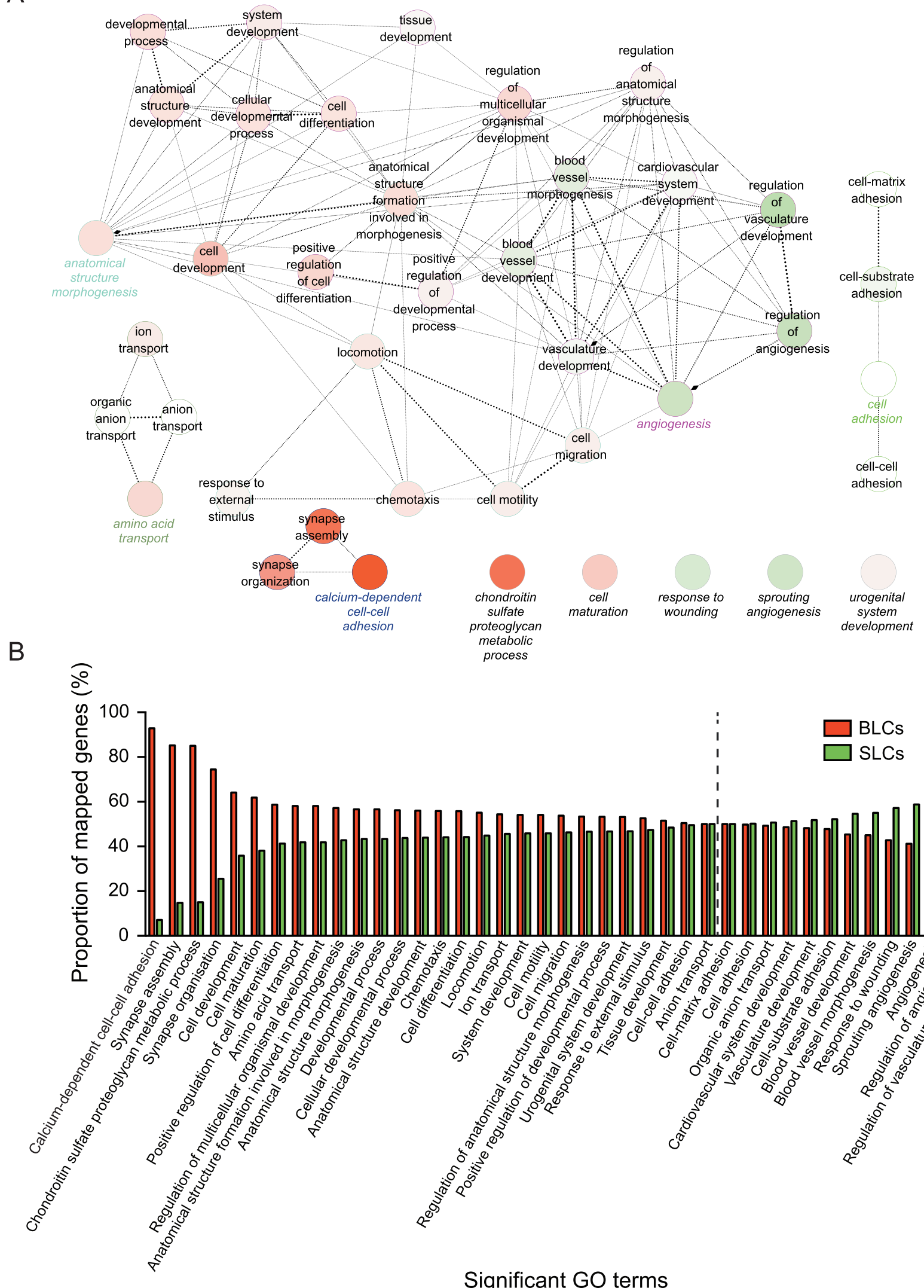
A

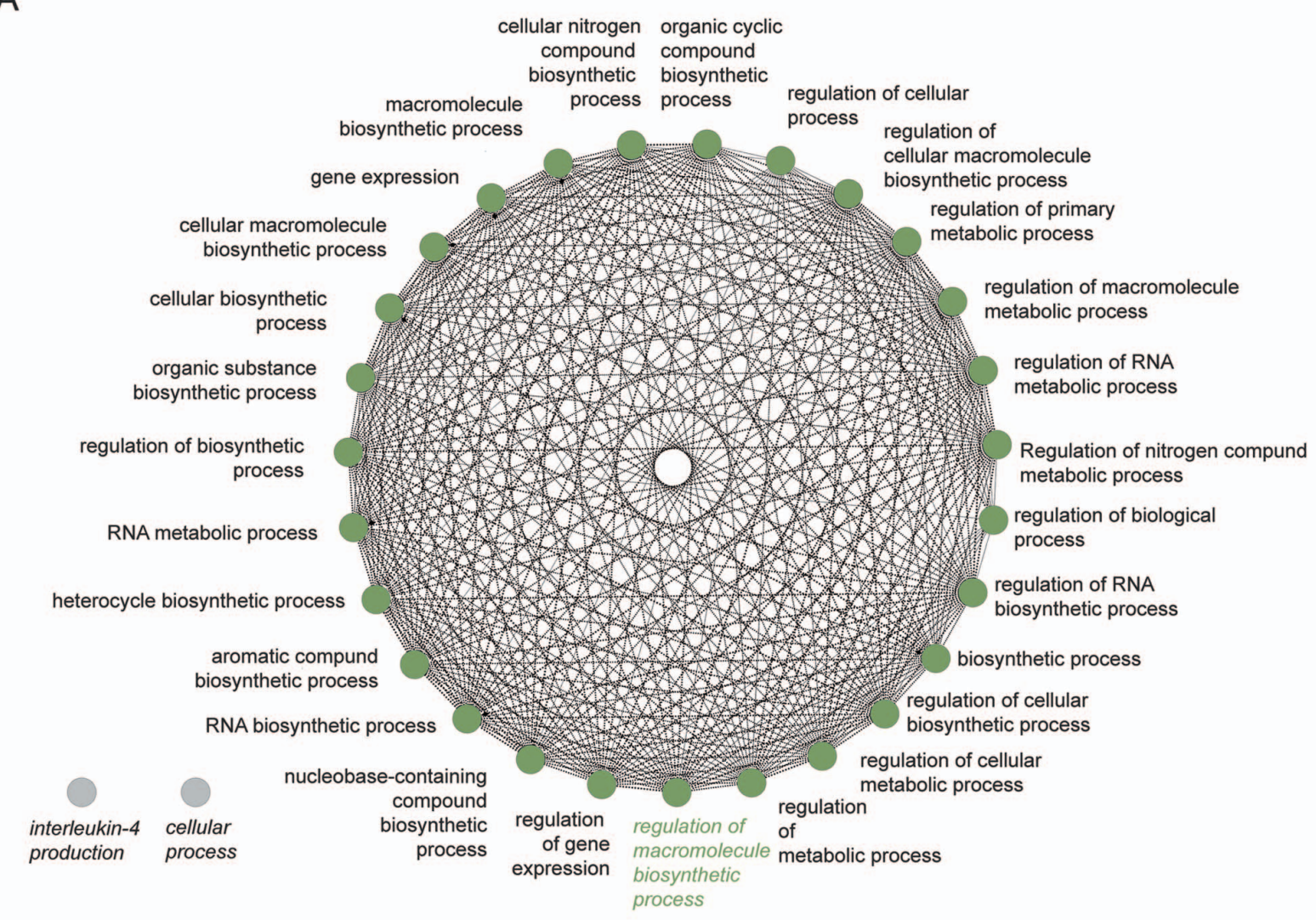

B

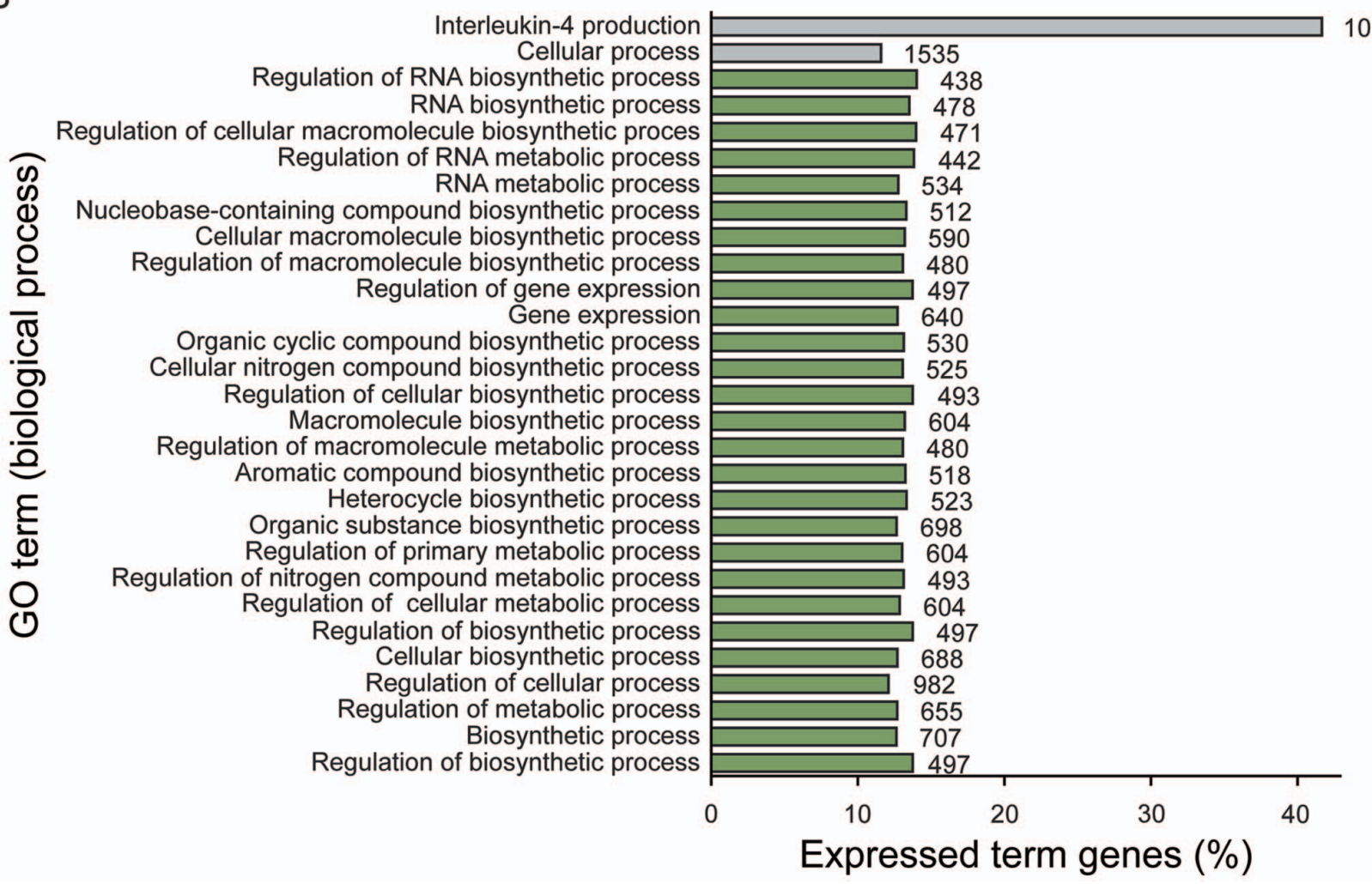

Figure 6. Gene ontology analysis of significantly upregulated genes in cornea. (A) Network of significantly enriched terms. (B) Bar chart of significantly enriched terms. Numbers next to the bars indicate total number of genes mapping to the specific term. doi:10.1371/journal.pone.0064244.g006 
A

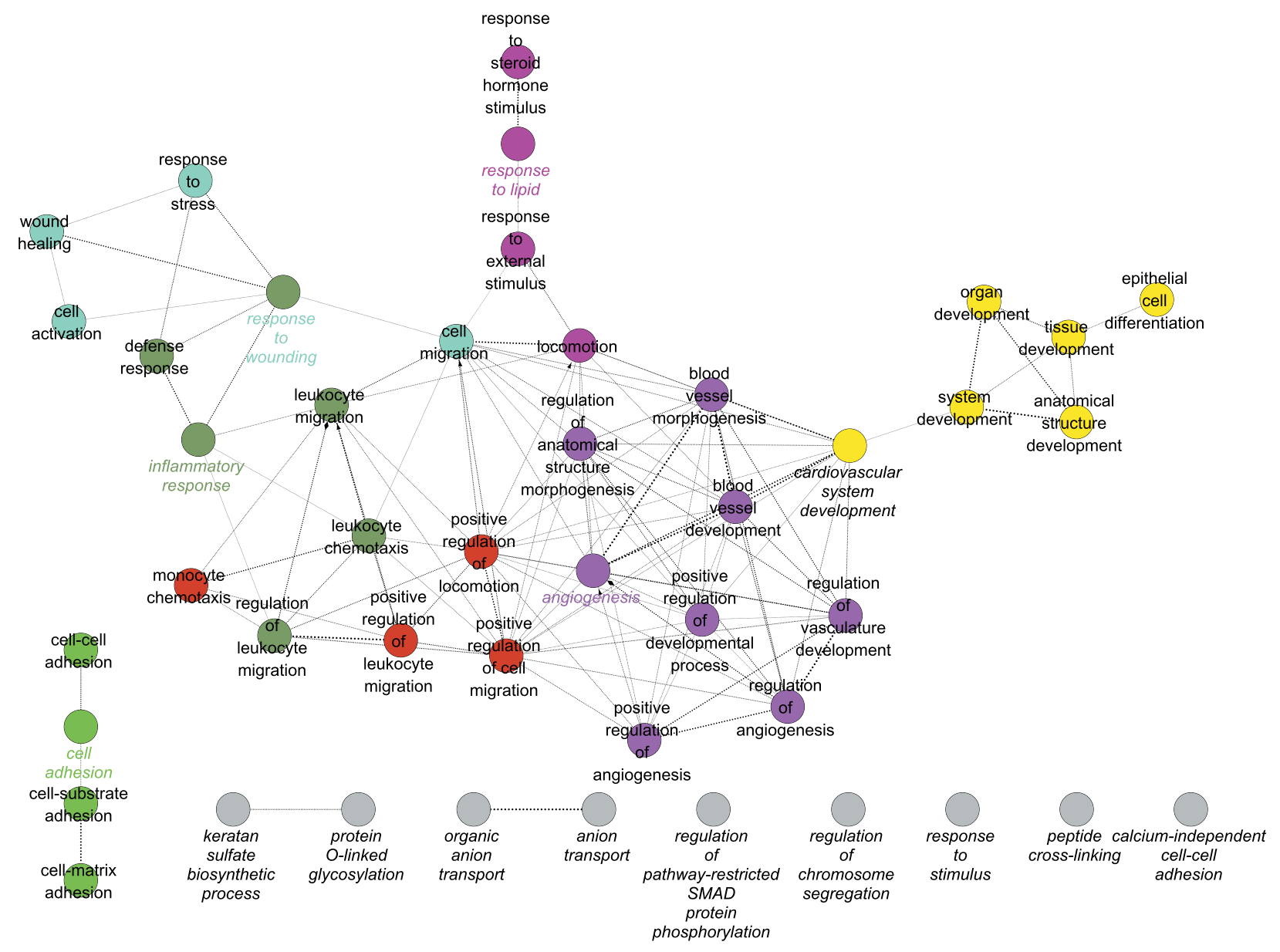

B

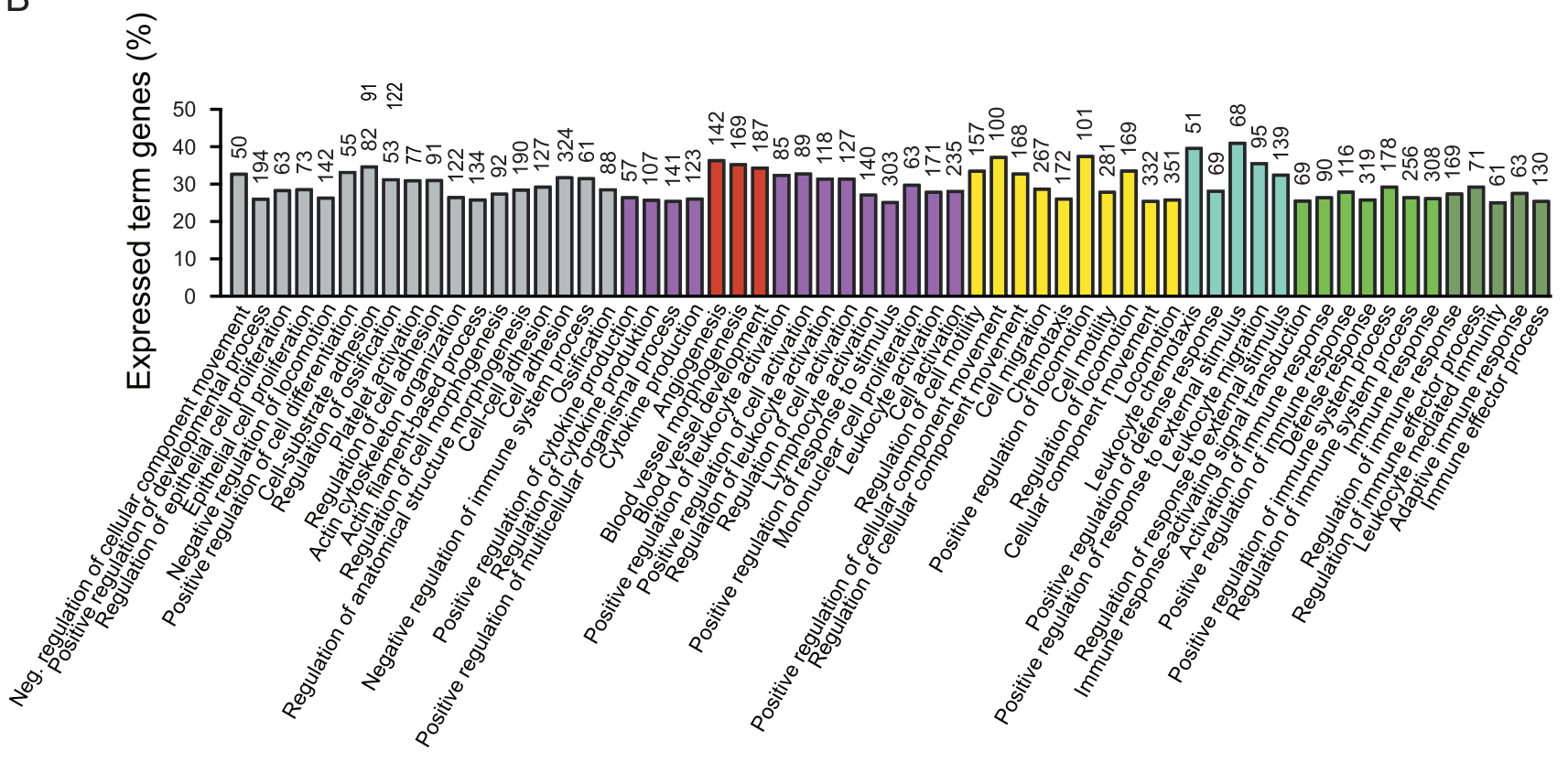

GO term (biological process)

Figure 7. Gene ontology analysis of significantly upregulated genes in stroma. (A) Network of significantly enriched terms. (B) Bar chart of significantly enriched terms. Numbers next to the bars indicate total number of genes mapping to the specific term. doi:10.1371/journal.pone.0064244.g007 
Table 1. Top 50 candidate LESC markers ${ }^{\mathrm{a}}$.

\begin{tabular}{|c|c|c|c|c|}
\hline Ensemble ID & Gene Symbol & Description & FDR p-value & RPKM \\
\hline ENSG00000143153 & ATP1B1 & ATPase, $\mathrm{Na}+/ \mathrm{K}+$ transporting, beta 1 polypeptide & 0.000449 & 10.25 \\
\hline ENSG00000158747 & NBL1 & neuroblastoma, suppression of tumorigenicity 1 & $2.75 \mathrm{E}-12$ & 5.25 \\
\hline ENSG00000144057 & ST6GAL2 & ST6 beta-galactosamide alpha-2,6-sialyltranferase 2 & 0 & 3.33 \\
\hline ENSG00000111850 & C6orf162 & chromosome 6 open reading frame 162 & 0.000013 & 2.26 \\
\hline ENSG00000135960 & EDAR & ectodysplasin A receptor & $6.68 \mathrm{E}-14$ & 2.21 \\
\hline ENSG00000113396 & SLC27A6 & solute carrier family 27 (fatty acid transporter), member 6 & 0 & 2.12 \\
\hline ENSG00000101191 & DIDO1 & death inducer-obliterator 1 & 0.03 & 2.07 \\
\hline ENSG00000256673 & RP11-599J14.2 & Known pseudogene & 0.000415 & 1.94 \\
\hline ENSG00000183495 & EP400 & E1A binding protein $\mathrm{p} 400$ & 2.37E-09 & 1.66 \\
\hline ENSG00000263050 & RP11-667K14.3 & Novel lincRNA & 0.000264 & 1.6 \\
\hline ENSG00000249742 & RP11-217E13.1 & Putative lincRNA & 0.000264 & 1.49 \\
\hline ENSG00000143228 & NUF2 & NUF2, NDC80 kinetochore complex component, homolog (S. cerevisiae) & 0.00000145 & 1.44 \\
\hline ENSG00000163067 & ZNF2 & zinc finger protein 2 & 4.14E-08 & 1.42 \\
\hline ENSG00000129810 & SGOL1 & shugoshin-like 1 (S. pombe) & 0.00959 & 1.23 \\
\hline ENSG00000114790 & ARHGEF26 & Rho guanine nucleotide exchange factor (GEF) 26 & 0.000041 & 1.16 \\
\hline ENSG00000185760 & KCNQ5 & potassium voltage-gated channel, KQT-like subfamily, member 5 & $6.91 \mathrm{E}-12$ & 1.15 \\
\hline ENSG00000259483 & RP11-930011.2 & Novel processed transcript & 0.02 & 1.03 \\
\hline ENSG00000254754 & RP11-20J1.1 & Putative lincRNA & 0.03 & 0.91 \\
\hline ENSG00000093009 & $\mathrm{CDC} 45$ & cell division cycle 45 homolog (S. cerevisiae) & 0.000084 & 0.89 \\
\hline ENSG00000169372 & CRADD & CASP2 and RIPK1 domain containing adaptor with death domain & 0.0021 & 0.85 \\
\hline ENSG00000260128 & ULK4P2 & unc-51-like kinase 4 (C. elegans) pseudogene 2 & $6.69 \mathrm{E}-08$ & 0.84 \\
\hline ENSG00000158301 & GPRASP2 & G protein-coupled receptor associated sorting protein 2 & 0.02 & 0.82 \\
\hline ENSG00000171126 & KCNG3 & potassium voltage-gated channel, subfamily G, member 3 & $6.12 \mathrm{E}-12$ & 0.81 \\
\hline ENSG00000254744 & CTD-3076017.1 & Novel antisense & 0.00553 & 0.8 \\
\hline ENSG00000250673 & RP11-6L6.2 & Putative protein coding & 0.03 & 0.8 \\
\hline ENSG00000196526 & AFAP1 & actin filament associated protein 1 & $3.01 \mathrm{E}-08$ & 0.79 \\
\hline ENSG00000151617 & EDNRA & endothelin receptor type $A$ & 0.000825 & 0.76 \\
\hline ENSG00000125257 & $\mathrm{ABCC} 4$ & ATP-binding cassette, sub-family C (CFTR/MRP), member 4 & $2.68 \mathrm{E}-09$ & 0.72 \\
\hline ENSG00000130669 & PAK4 & p21 protein (Cdc42/Rac)-activated kinase 4 & 0.00222 & 0.72 \\
\hline ENSG00000177098 & SCN4B & sodium channel, voltage-gated, type IV, beta subunit & 0.0000106 & 0.72 \\
\hline ENSG00000106665 & CLIP2 & CAP-GLY domain containing linker protein 2 & 0.02 & 0.71 \\
\hline ENSG00000112530 & PACRG & PARK2 co-regulated & 0.04 & 0.7 \\
\hline ENSG00000174827 & PDZK1 & PDZ domain containing 1 & 0.0000244 & 0.69 \\
\hline ENSG00000140093 & SERPINA10 & $\begin{array}{l}\text { serpin peptidase inhibitor, clade A (alpha-1 antiproteinase, antitrypsin), } \\
\text { member } 10\end{array}$ & 0.00125 & 0.69 \\
\hline ENSG00000123473 & STIL & $\mathrm{SCL} / \mathrm{TAL} 1$ interrupting locus & 0.000000555 & 0.69 \\
\hline ENSG00000102858 & MGRN1 & mahogunin ring finger 1 , E3 ubiquitin protein ligase & 0.00111 & 0.67 \\
\hline ENSG00000186715 & MST1P9 & macrophage stimulating 1 (hepatocyte growth factor-like) pseudogene 9 & 0.000000182 & 0.61 \\
\hline ENSG00000261777 & RP11-529K1.2 & Novel processed transcript & 0.0000735 & 0.61 \\
\hline ENSG00000134253 & TRIM45 & tripartite motif containing 45 & 0.03 & 0.61 \\
\hline ENSG00000203872 & C6orf163 & chromosome 6 open reading frame 163 & 0.0092 & 0.59 \\
\hline ENSG00000255263 & RP11-718B12.3 & Putative antisense & 0.00359 & 0.57 \\
\hline ENSG00000225377 & RP5-1103G7.4 & Novel antisense & 0.01 & 0.57 \\
\hline ENSG00000215760 & TAF9BP2 & $\begin{array}{l}\text { TAF9B RNA polymerase II, TATA box binding protein (TBP)-associated factor, } \\
31 \text { kDa pseudogene } 2\end{array}$ & 0.05 & 0.57 \\
\hline ENSG00000158813 & EDA & ectodysplasin A & 0.00105 & 0.56 \\
\hline ENSG00000248125 & CTB-73N10.1 & Novel lincRNA & 0.000974 & 0.55 \\
\hline ENSG00000236215 & $\mathrm{RP} 11-262 \mathrm{H} 14.10$ & Known pseudogene & 0.05 & 0.55 \\
\hline ENSG00000235167 & RP11-425M5.5 & Putative processed transcript & 0.00854 & 0.54 \\
\hline ENSG00000095627 & TDRD1 & tudor domain containing 1 & $4.03 E-11$ & 0.54 \\
\hline
\end{tabular}


Table 1. Cont.

\begin{tabular}{lllll}
\hline & & & & \\
\hline Ensemble ID & Gene Symbol & Description & FDR p-value & RPKM \\
\hline ENSG00000125319 & C17orf53 & chromosome 17 open reading frame 53 & 0.02 & 0.52 \\
ENSG00000253983 & RP1-16A9.1 & Novel antisense & 0.02 & 0.51 \\
\hline
\end{tabular}

${ }^{\mathrm{a} G e n e s}$ with uniquely identified transcript in BLCs, q-value $<0.05$, and higher RPKM values than SLCs.

doi:10.1371/journal.pone.0064244.t001

nature when compared with BLCs or SLCs. Most GO categories represent biosynthetic processes or regulation of biosynthetic processes. Only one large group of GO terms $(>3)$ could be created based on the list of upregulated genes, and the leading term was Regulation of Macromolecule Biosynthetic Process.

\section{GO Analysis of Differentially Expressed Genes in Stroma}

The GO analysis and network mapping for stroma is depicted in figure 7. A much more diverse group of functions was observed in this compartment than in the epithelial counterparts. Being a part of the LESC niche, it was conceivable that some molecular crosstalk between the stroma and BLCs would be revealed. Indeed, several significant GO terms related to development like Regulation of Anatomical Structure Morphogenesis and Positive Regulation of Developmental Process were identified. Additional significant terms indicating influence on epithelium included Regulation of Epithelial Cell Proliferation, and Epithelial Cell Proliferation. Other diverse functions in stroma were related to immunological function, regulation of vessel development, signaling, and cell adhesion.

\section{Uniquely Expressed Genes in BLCs}

Using a highly powerful combination of LCM and RNA sequencing to detect novel biomarkers for LESGs, we furnish, based on the expression levels, a list of top 50 unique genes in Table 1 and a fully comprehensive list in supporting material (Table S3). As especially interesting appears the NBL1, which is known to be able to suppress Wnt signaling as a BMP antagonist. Thus it is plausible that it plays a role in the maintenance of LESCis. Another very interesting candidate gene is EDAR from the subfamily of TNFR. This gene encodes the conserved ectodysplasin A receptor, that is responsible for interactions both between mesoderm and ectoderm and within ectoderm, and is vital for normal skin embryological development [37]. The DIDO1 is closely related to DIDO3, which has very recently been shown to be involved in stem cell development [38]. The xenobiotic transporter ABCC4 (Multidrug resistance-associated protein 4) from the ATP-binding cassette (ABC) superfamily can also be found in this list. The function of this transporter could be of protective nature. The hallmark of stem cell compartments is tight regulation with regard to cell cycle and apoptotic events. In this context, it is not surprising that the CDC45 (cell division control protein 45 homolog) is being listed as well, along with the GRADD (RAIDD) that triggers apoptotic processes [39], and PAK4, which is known to enhance cell survival. We also found EDNRA in this compartment, intriguingly close to the vascular limbal network in stroma. EDNRA has been shown to interact with Tip60 (histone acetyltransferase) and HDAC7 (histone deacetylase) [40], thereby possibly affecting expression patterns within the cell.

\section{Uniquely Expressed Genes in Cornea}

Table 2 lists the top 50 genes based on RPKM values and the full list of possible differentiation markers is included in the Table
S4. Of the most notable genes, the NGK is a member of NGK adapter protein family and has been implicated in regulation of receptor tyrosine kinases and cytoskeletal organization. STOX1 is structurally and functionally correlated to forkhead transcription factors [41,42], and functions as a transcription factor regulated by the PI3K-Akt pathway. Expression of STOX1 has been implicated in cell cycle control [43].

\section{Discussion}

The present investigation is, to the best of our knowledge, the first study to couple a highly expedited tissue harvest with the selectivity of laser capture and the extreme depth of massive parallel sequencing to obtain in vivo-relevant transcriptomic profiles of differentiation-specific corneal compartments with unprecedented resolution. Previously, attempts have been made to perform transcriptional profiling of corneal epithelium using older technology based on microarrays [44], tissue from other species [45], culture systems [46], or potentially deteriorated samples from cadavers [44,47]. Selection of appropriate transcriptional analysis appeared central to our investigation, since the stem cells are believed to exist in niches in low-numbers as small [48] and dormant cells [19], and the rare transcripts may thus avoid detection in case of inappropriate technology. Very important was also optimization of the harvest procedure to less than five minutes, as it has been shown that the duration of cold ischemia beyond this interval results in progressively altered gene expression [49]. The location of differentiated cells in cornea, migratory activated cells in SLCs, and primitive precursor cells in BLCs was confirmed by GO analysis and lent further support for the current concept of corneal homeostasis [18].

The SLCs represent a site with major prevalence of TACs as they migrate centripetally and superficially and differentiate into PMCs and TDCs. In addition to significant GO terms related to migration and epithelial cell differentiation, we also found a plethora of significantly upregulated genes involved in angiogenesis. Among the 72 genes that mapped to vessel-related ontology terms, it is especially the flt l, which stands out. Importantly, expression of several short isoforms, which are known to be soluble, was confirmed. This finding may be an answer to a longstanding conundrum as to how the cornea maintains its avascularity and may provide further support for previously reported results [50]. This information could also partly explain angiogenic disturbances frequently observed in limbal stem cell deficiency (LSCD). Further analysis of the individual genes highlighted in our study should yield a better understanding of the mechanisms implicated in the control of limbal vasculature.

The primitive nature of the BLC compartment was evident from both KEGG mapping and upregulated GO terms. The most prominent terms related to developmental pathways and included terms such as Cell Development and Negative Regulation of Canonical Wnt Receptor Signaling Pathway. It is indeed Wnt signaling, that is recognized as a central player in stem cell activation [51]. Another very interesting finding, which could be specifically attributed to 
Table 2. Top 50 candidate differentiation markers ${ }^{\mathrm{a}}$.

\begin{tabular}{|c|c|c|c|c|}
\hline Ensemble ID & Gene Symbol & Description & FDR p-value & RPKM \\
\hline ENSG00000137460 & FHDC1 & FH2 domain containing 1 & $1.99 \mathrm{E}-14$ & 3.83 \\
\hline ENSG00000184887 & BTBD6 & BTB (POZ) domain containing 6 & $3.85 \mathrm{E}-07$ & 3.56 \\
\hline ENSG00000071051 & NCK2 & NCK adaptor protein 2 & $1.60 \mathrm{E}-09$ & 2.94 \\
\hline ENSG00000165730 & STOX1 & storkhead box 1 & $1.14 \mathrm{E}-03$ & 2.26 \\
\hline ENSG00000169379 & ARL13B & ADP-ribosylation factor-like $13 \mathrm{~B}$ & 0 & 2.12 \\
\hline ENSG00000125898 & FAM110A & family with sequence similarity 110 , member $A$ & $2.15 \mathrm{E}-09$ & 2.04 \\
\hline ENSG00000229109 & RP11-439K3.1 & Putative antisense & $8.69 \mathrm{E}-05$ & 1.91 \\
\hline ENSG00000228470 & RP11-176D17.3 & Novel processed transcript & 0.02 & 1.88 \\
\hline ENSG00000249955 & RP11-6E9.4 & Novel antisense & $1.19 \mathrm{E}-03$ & 1.82 \\
\hline ENSG00000162076 & FLYWCH2 & FLYWCH family member 2 & 0.04 & 1.66 \\
\hline ENSG00000263041 & RP11-355F22.1 & Known processed transcript & 2.94E-05 & 1.49 \\
\hline ENSG00000198945 & L3MBTL3 & I(3)mbt-like 3 (Drosophila) & 7.78E-09 & 1.46 \\
\hline ENSG00000257542 & OR7E5P & olfactory receptor, family 7 , subfamily $E$, member 5 pseudogene & $1.04 \mathrm{E}-04$ & 1.46 \\
\hline ENSG00000224616 & RP11-305E17.6 & Novel antisense & $5.43 \mathrm{E}-03$ & 1.41 \\
\hline ENSG00000173610 & UGT2A1 & UDP glucuronosyltransferase 2 family, polypeptide $A 1$, complex locus & 0 & 1.29 \\
\hline ENSG00000145864 & GABRB2 & gamma-aminobutyric acid (GABA) A receptor, beta 2 & 0 & 1.18 \\
\hline ENSG00000148300 & REXO4 & REX4, RNA exonuclease 4 homolog (S. cerevisiae) & $2.93 \mathrm{E}-04$ & 1.14 \\
\hline ENSG00000236624 & CCDC163P & coiled-coil domain containing 163 , pseudogene & $4.52 \mathrm{E}-07$ & 0.96 \\
\hline ENSG00000260548 & RP6-24A23.6 & Putative protein coding & $3.27 \mathrm{E}-03$ & 0.95 \\
\hline ENSG00000185437 & SH3BGR & SH3 domain binding glutamic acid-rich protein & $2.05 \mathrm{E}-03$ & 0.95 \\
\hline ENSG00000120217 & CD274 & CD274 molecule & $5.17 \mathrm{E}-12$ & 0.93 \\
\hline ENSG00000089041 & P2RX7 & purinergic receptor $\mathrm{P} 2 \mathrm{X}$, ligand-gated ion channel, 7 & $1.57 \mathrm{E}-06$ & 0.9 \\
\hline ENSG00000171428 & NAT1 & $\mathrm{N}$-acetyltransferase 1 (arylamine $\mathrm{N}$-acetyltransferase) & 0.02 & 0.87 \\
\hline ENSG00000138669 & PRKG2 & protein kinase, cGMP-dependent, type II & $1.03 \mathrm{E}-14$ & 0.75 \\
\hline ENSG00000239388 & ASB14 & ankyrin repeat and SOCS box containing 14 & $5.90 \mathrm{E}-05$ & 0.73 \\
\hline ENSG00000254731 & CTD-2005H7.1 & Novel lincRNA & 0.04 & 0.73 \\
\hline ENSG00000134256 & CD101 & CD101 molecule & $4.96 \mathrm{E}-03$ & 0.68 \\
\hline ENSG00000260281 & RP11-329J18.2 & Novel antisense & 0.01 & 0.65 \\
\hline ENSG00000197093 & GAL3ST4 & galactose-3-O-sulfotransferase 4 & $1.26 \mathrm{E}-07$ & 0.62 \\
\hline ENSG00000066185 & ZMYND12 & zinc finger, MYND-type containing 12 & $1.24 \mathrm{E}-03$ & 0.6 \\
\hline ENSG00000236123 & CEACAMP11 & carcinoembryonic antigen-related cell adhesion molecule pseudogene 11 & 0.03 & 0.59 \\
\hline ENSG00000050030 & KIAA2022 & Known protein coding & $5.67 \mathrm{E}-06$ & 0.59 \\
\hline ENSG00000255647 & AC093510.1 & Known pseudogene & 0.03 & 0.52 \\
\hline ENSG00000253549 & RP11-317J10.2 & Novel antisense & $1.59 \mathrm{E}-03$ & 0.48 \\
\hline ENSG00000248371 & CTC-347C20.2 & Putative lincRNA & 0.02 & 0.46 \\
\hline ENSG00000166321 & NUDT13 & nudix (nucleoside diphosphate linked moiety X)-type motif 13 & 0.05 & 0.46 \\
\hline ENSG00000233639 & AC018730.1 & Novel antisense & 0.02 & 0.45 \\
\hline ENSG00000188820 & FAM26F & family with sequence similarity 26 , member $F$ & $3.27 \mathrm{E}-03$ & 0.45 \\
\hline ENSG00000236409 & NRADDP & neurotrophin receptor associated death domain, pseudogene & 0.04 & 0.45 \\
\hline ENSG00000141028 & CDRT15P1 & CMT1A duplicated region transcript 15 pseudogene 1 & 0.03 & 0.44 \\
\hline ENSG00000251584 & RP11-440114.3 & Putative lincRNA & 0.03 & 0.44 \\
\hline ENSG00000257052 & RP11-881M11.2 & Novel antisense & 0.03 & 0.43 \\
\hline ENSG00000183423 & LRIT3 & leucine-rich repeat, immunoglobulin-like and transmembrane domains 3 & $2.92 \mathrm{E}-04$ & 0.41 \\
\hline ENSG00000152208 & GRID2 & glutamate receptor, ionotropic, delta 2 & $5.36 \mathrm{E}-14$ & 0.4 \\
\hline ENSG00000253479 & RP11-744J10.3 & Novel lincRNA & 0.05 & 0.4 \\
\hline ENSG00000182814 & FUNDC2P2 & FUN14 domain containing 2 pseudogene 2 & $6.79 \mathrm{E}-03$ & 0.39 \\
\hline ENSG00000137766 & UNC13C & unc-13 homolog C (C. elegans) & $6.24 \mathrm{E}-14$ & 0.39 \\
\hline ENSG00000184374 & COLEC10 & collectin sub-family member 10 (C-type lectin) & $3.80 \mathrm{E}-03$ & 0.38 \\
\hline
\end{tabular}


Table 2. Cont.

\begin{tabular}{lllll}
\hline Ensemble ID & Gene Symbol & Description & FDR p-value & RPKM \\
\hline ENSG00000165807 & PPP1R36 & protein phosphatase 1, regulatory subunit 36 & $1.19 E-05$ & 0.37 \\
ENSG00000203871 & C6orf164 & Known protein coding & 0.02 & 0.36 \\
\hline
\end{tabular}

${ }^{\mathrm{a} G e n e s}$ with uniquely identified transcripts in cornea, q-value $<0.05$, and higher RPKM values than SLCs.

doi:10.1371/journal.pone.0064244.t002

the BLCs, involved identification of highly active pigmentation processes. Only the cells in BLCs are known to acquire a pigment cap, that is presumed to protect LESCs from UV-induced damage [36]. Furthermore, our data appear to highlight a novel link between the processes underlying the development and homeostasis of BLCs. It has been suggested that during development, the neural crest-derived Sox $10^{+}$Schwann cell precursors (SCPs) along peripheral nerves are directed to melanocyte fate by microphtalmia-associated transcription factor (MITF) [52]. Our investigation of BLCs in the developed limbus indicates as well, high activity of processes in the categories covering Neural Crest Cell Development and Neural Crest Cell Differentiation, entailing most noteworthy upregulation of SOX10 and MITF. It thus appears, that at least some aspects of the maintenance of cornea are governed by mechanisms that are analogous to those taking place during embryogenesis.

In addition to cell development, it was processes related to innervation that scored high in the analysis of BLCs, underscoring yet another possible dimension in the control of limbal homeostasis. Very recently, limbal innervation was shown to maintain LESCs, as these stem cells were lost in a neurotrophic keratopathy mouse model [53]. Similarly, sub basal nerve plexus was recently confirmed to be absent from human patients suffering from LSCD, as evident from in vivo confocal analysis [54]. Based on this evidence, one is tempted to surmise that the presence of corneal epithelial wounds could be signaled to LESCs by neural mechanisms in order to initiate the regenerative process. Taken together, the accumulated data clearly indicate that uncompromised crosstalk between LESCs and the nervous system is essential for the limbal integrity.

In an effort to identify novel LESG biomarkers, our attention was drawn to a small group of three genes including Lrig1, NFATc1, and SOX9. In the current study Lrigl has been found specifically upregulated in the BLGs, and previously, it has been implicated in the control of epidermal stem cell quiescence $[55,56]$. Assuming a role in the context of homeostasis of other tissues, the family of Lrig genes appears especially pertinent. In epidermis, Lrigl has been recognized to play a major role, as mentioned earlier, but co-expression with other family member Lgr6 seems important as well [57]. The resemblance of epidermal expression profile, involving Lrg 1 and Lgr6 but not Lgr5, with that of the BLCs, thus points to the similarity of processes involved in the regulation of these two niches. The significance of Lrigl as a possible LESC marker is further substantiated by the recent data emphasizing its role in intestinal stem cell homeostasis [58]. Hence, we propose that Lrigl, along with other family members, should be further studied as a major in and ex vivo candidate marker. Other interesting candidates were found among the genes, which were uniquely and significantly expressed in either the stem cell or the differentiation niches. Ongoing and future work is aimed to shed more light on the significance of the proposed biomarkers.
Finally, as it has previously been shown that hypoxia supports stemness of ex vivo expanded stem cells [7,59-61], it was of special interest to explore whether the high level of transcriptomic detail could contribute to our understanding of hypoxic regulations in the limbal niche. Analysis provided a complex picture, where the hypoxic nature of the niche was corroborated by upregulation of downstream targets for HIF-1, such as the PGF (placental growth factor), VEGFA (vascular endothelial factor A), and VEGFG (vascular endothelial factor $\mathrm{C}$ ). On the other hand, the activation of prolylhydroxylases PHD1 and PHD2 indicated that mechanisms are in place that tend to mitigate the effect of HIF signaling. Of interest was also finding an upregulation of the pro-survival gene BCL2, which has previously been shown to enhance survival of embryonic stem cells [62]. The hypoxic networks in the limbal niche thus appear complex, nevertheless, our data confirm that oxygen is a factor, which needs to be recognized as one of the pivotal factors controlling the maintenance of stem cells.

Surprisingly, we did not find any significant ABCG2 expression in the BLCs. This membrane bound transporter is responsible for the efflux of Hoechst 33342, thereby providing for the so-called side population believed to include stem cells $[15,63]$. This could be explained by either a true lack of expression in the particular cryosections [15] or that this particular transcript has escaped assembly by the employed algorithm. The first alternative seems more plausible, as the accuracy of laser capture microdissection was evident from high expression of presumed stem cell markers $\Delta \mathrm{Np} 63 \alpha[4,64,65]$ and cytokeratin 19 [66-68] and conversely low expression of presumed differentiation markers cytokeratin 3 [69] and connexin 43 [15]. Intriguingly, we did find in BLCs a high and unique expression of the family member ABCC4. Regarding the cytokeratin 19, this molecule lends itself as a convenient marker to diagnose LSCD by impression cytology [70], since it is absent in the central corneal epithelial cells [71]. Furthermore, KRT19 has previously been suggested to be a marker of epidermal stem cells [72], stem cells in the hair follicle [73], the side population of conjunctival epithelial cells [74], basal epithelial cells in corneal limbus [66-68], and basal cells of limbal epithelial stem cell cultures $[6,75,76]$. Recently, KRT19 was also found upregulated in limbal crypts based on microarray analysis [44]. Our own data thus appear to corroborate the previous observations.

Due to the highly stringent requirements in the tissue selection process, we were not able to include additional donors in our study, and thereby further biological replicates. We aimed to balance this limitation by using rigorous criteria for the selection of the genes. As it is beyond the scope of the current paper to provide comprehensive information on all mapped genes, ongoing work will further elucidate the role of individual biomarkers, activated pathways, and interplay between the stem cells and the surroundings. It is expected that this new information will contribute to further refinement of conditions for ex vivo expansion 
of LESCs, increase the quality of grafts prior to CLET, and at the same time enable new ways of diagnosing the LSCD.

\section{Supporting Information}

Figure S1 Gene ontology analysis of genes within the leading term Cell Development in BLGs. (A) Network of significantly enriched terms. (B) Bar chart of significantly enriched terms. Numbers next to the bars indicate total number of genes mapping to the specific term.

(EPS)

\section{References}

1. Pellegrini G, Traverso CE, Franzi AT, Zingirian M, Cancedda R, et al. (1997) Long-term restoration of damaged corneal surfaces with autologous cultivated corneal epithelium. The Lancet 349: 990-993. doi:10.1016/S01406736(96)11188-0.

2. Rheinwald JG, Green H (1975) Formation of a keratinizing epithelium in culture by a cloned cell line derived from a teratoma. Cell 6: 317-330.

3. Rheinwald JG, Green H (1975) Serial cultivation of strains of human epidermal keratinocytes: the formation of keratinizing colonies from single cells. Cell 6: 331-343.

4. Rama P, Matuska S, Paganoni G, Spinelli A, de Luca M, et al. (2010) Limbal Stem-Cell Therapy and Long-Term Corneal Regeneration. N Engl J Med 363: 147-155. doi:10.1056/NEJMoa0905955.

5. Lekhanont K, Choubtum L, Chuck RS, Sa-ngiampornpanit T, Chuckpaiwong $\mathrm{V}$, et al. (2009) A serum- and feeder-free technique of culturing human corneal epithelial stem cells on amniotic membrane. Mol Vis 15: 1294-1302.

6. Meyer-Blazejewska EA, Kruse FE, Bitterer K, Meyer C, Hofmann-Rummelt C, et al. (2010) Preservation of the Limbal Stem Cell Phenotype by Appropriate Culture Techniques. Invest Ophthalmol Vis Sci 51: 765-774. doi:10.1167/ iovs.09-4109.

7. Bath C, Sufangg Y, Muttuvelu D, Fink T, Emmersen J, et al. (2013) Hypoxia is a key regulator of limbal epithelial stem cell growth and differentiation. Stem Cell Research 10: 349-360. doi:10.1016/j.scr.2013.01.004.

8. Shahdadfar A, Haug K, Pathak M, Drolsum L, Olstad OK, et al. (2012) Ex vivo expanded autologous limbal epithelial cells on amniotic membrane using a culture medium with human serum as single supplement. Exp Eye Res 97: 1-9. doi:10.1016/j.exer.2012.01.013

9. Chen B, Mi S, Wright B, Connon CJ (2010) Differentiation Status of Limbal Epithelial Cells Cultured on Intact and Denuded Amniotic Membrane Before and After Air-Lifting. Tissue engineering Part A 16: 2721-2729. doi:10.1089/ ten.tea.2009.0711.

10. Di Girolamo N, Di Girolamo N, Bosch M, Bosch M, Zamora K, et al. (2009) A Contact Lens-Based Technique for Expansion and Transplantation of Autologous Epithelial Progenitors for Ocular Surface Reconstruction. Transplantation 87: 1571-1578. doi:10.1097/TP.0b013e3181a4bbf2.

11. Jones RR, Hamley IW, Connon CJ (2012) Ex vivo expansion of limbal stem cells is affected by substrate properties. Stem Cell Research 8: 403-409. doi:10.1016/ j.scr.2012.01.001.

12. Sharma SM, Fuchsluger T, Ahmad S, Katikireddy KR, Armant M, et al. (2012) Comparative analysis of human-derived feeder layers with 3T3 fibroblasts for the ex vivo expansion of human limbal and oral epithelium. Stem Cell Rev and Rep 8: 696-705. doi:10.1007/s12015-011-9319-6.

13. Notara M, Haddow DB, MacNeil S, Daniels JT (2007) A xenobiotic-free culture system for human limbal epithelial stem cells. Regen Med 2: 919-927. doi: $10.2217 / 17460751.2 .6 .919$

14. Mariappan I, Maddileti S, Savy S, Tiwari S, Gaddipati S, et al. (2010) In vitro culture and expansion of human limbal epithelial cells. Nat Protoc 5: 14701479. doi:10.1038/nprot.2010.115.

15. Wolosin JM (2006) Cell markers and the side population phenotype in ocular surface epithelial stem cell characterization and isolation. Ocul Surf 4: 10-23.

16. Mann I (1944) A study of epithelial regeneration in the living eye. Br J Ophthalmol 28: 26-40.

17. Davanger M, Evensen A (1971) Role of the pericorneal papillary structure in renewal of corneal epithelium. Nature 229: 560-561.

18. Thoft RA, Friend J (1983) The X, Y, Z hypothesis of corneal epithelial maintenance. Invest Ophthalmol Vis Sci 24: 1442-1443.

19. Cotsarelis G, Cheng SZ, Dong G, Sun TT, Lavker RM (1989) Existence of slowcycling limbal epithelial basal cells that can be preferentially stimulated to proliferate: implications on epithelial stem cells. Cell 57: 201-209. doi:10.1016/ 0092-8674(89)90958-6.

20. Huang AJ, Tseng SC (1991) Corneal epithelial wound healing in the absence of limbal epithelium. Invest Ophthalmol Vis Sci 32: 96-105.

21. Lehrer MS, Sun TT, Lavker RM (1998) Strategies of epithelial repair: modulation of stem cell and transit amplifying cell proliferation. J Cell Sci 111 (Pt 19): 2867-2875.

22. Nagasaki T, Zhao J (2003) Centripetal movement of corneal epithelial cells in the normal adult mouse. Invest Ophthalmol Vis Sci 44: 558-566.

\section{Acknowledgments}

The expert technical assistance of Ole Jensen and Helle Skjødt Møller is highly appreciated. We also thank the staff at the veterinary facilities of the Aarhus and Aalborg university hospitals for their help in obtaining fresh pig tissue for initial pilot experiments.

\section{Author Contributions}

Conceived and designed the experiments: CB JE HV JH VZ. Performed the experiments: CB DM. Analyzed the data: CB JE HV JH VZ. Contributed reagents/materials/analysis tools: CB JE JH VZ. Wrote the paper: CB JE HV JH VZ.

23. Shortt AJ, Secker GA, Munro PM, Khaw PT, Tuft SJ, et al. (2007) Characterization of the Limbal Epithelial Stem Cell Niche: Novel Imaging Techniques Permit In Vivo Observation and Targeted Biopsy of Limbal Epithelial Stem Cells. Stem Cells 25: 1402-1409. doi:10.1634/stemcells.20060580 .

24. Schofield R (1978) The relationship between the spleen colony-forming cell and the haemopoietic stem cell. Blood Cells 4: 7-25.

25. Dua HS (2005) Limbal epithelial crypts: a novel anatomical structure and a putative limbal stem cell niche. British Journal of Ophthalmology 89: 529-532. doi:10.1136/bjo.2004.049742.

26. Emmert-Buck MR, Bonner RF, Smith PD, Chuaqui RF, Zhuang Z, et al. (1996) Laser capture microdissection. Science 274: 998-1001.

27. Espina V, Wulfkuhle JD, Calvert VS, VanMeter A, Zhou W, et al. (2006) Lasercapture microdissection. Nat Protoc 1: 586-603. doi:10.1038/nprot.2006.85.

28. Espina V, Heiby M, Pierobon M, Liotta LA (2007) Laser capture microdissection technology. Expert Rev Mol Diagn 7: 647-657. doi:10.1586/ 14737159.7.5.647

29. Wang Z, Gerstein M, Snyder M (2009) RNA-Seq: a revolutionary tool for transcriptomics. Nat Rev Genet 10: 57-63. doi:10.1038/nrg2484.

30. Mortazavi A, Williams BA, McCue K, Schaeffer L, Wold B (2008) Mapping and quantifying mammalian transcriptomes by RNA-Seq. Nat Meth 5: 621-628. doi:10.1038/nmeth. 1226 .

31. Davanian H, Stranneheim H, Båge T, Lagervall M, Jansson L, et al. (2012) Gene expression profiles in paired gingival biopsies from periodontitis-affected and healthy tissues revealed by massively parallel sequencing. PLoS ONE 7: e46440. doi:10.1371/journal.pone.0046440.

32. Bindea G, Mlecnik B, Hackl H, Charoentong P, Tosolini M, et al. (2009) ClueGO: a Cytoscape plug-in to decipher functionally grouped gene ontology and pathway annotation networks. Bioinformatics 25: 1091-1093. doi:10.1093/ bioinformatics/btp 101

33. Shannon P, Markiel A, Ozier O, Baliga NS, Wang JT, et al. (2003) Cytoscape: a software environment for integrated models of biomolecular interaction networks. Genome research 13: 2498-2504.

34. Kal AJ, van Zonneveld AJ, Benes V, van den Berg M, Koerkamp MG, et al. (1999) Dynamics of gene expression revealed by comparison of serial analysis of gene expression transcript profiles from yeast grown on two different carbon sources. Mol Biol Cell 10: 1859-1872.

35. Benjamini Y, Hochberg Y (1995) Controlling the false discovery rate: a practical and powerful approach to multiple testing. Journal of the Royal Statistical Society Series B (Methodological): 289-300.

36. Higa K, Shimmura S, Miyashita H, Shimazaki J, Tsubota K (2005) Melanocytes in the corneal limbus interact with K19-positive basal epithelial cells. Exp Eye Res 81: 218-223. doi:10.1016/j.exer.2005.01.023.

37. Mikkola ML (2010) The Edar Subfamily in Hair and Exocrine Gland Development. Advances in Experimental Medicine and Biology. Advances in Experimental Medicine and Biology. New York, NY: Springer New York, Vol. 691. 23-33. doi:10.1007/978-1-4419-6612-4_3.

38. Fütterer A, Raya A, Llorente M, Izpisúa-Belmonte JC, la Pompa de JL, et al. (2012) Ablation of Dido3 compromises lineage commitment of stem cells in vitro and during early embryonic development. Cell Death Differ 19: 132-143. doi:10.1038/cdd.2011.62

39. Berube C, Boucher L-M, Ma W, Wakeham A, Salmena L, et al. (2005) Apoptosis caused by p53-induced protein with death domain (PIDD) depends on the death adapter protein RAIDD. Proc Natl Acad Sci USA 102: 14314-14320. doi: $10.1073 /$ pnas.0506475102.

40. Lee HJ, Chun M, Kandror KV (2001) Tip60 and HDAC7 interact with the endothelin receptor a and may be involved in downstream signaling. J Biol Chem 276: 16597-16600. doi:10.1074/jbc.C000909200.

41. van Dijk M, van Bezu J, van Abel D, Dunk C, Blankenstein MA, et al. (2010) The STOX1 genotype associated with pre-eclampsia leads to a reduction of trophoblast invasion by alpha-T-catenin upregulation. Human Molecular Genetics 19: 2658-2667. doi:10.1093/hmg/ddq152.

42. van Dijk M, Oudejans CBM (2011) STOX1: Key Player in Trophoblast Dysfunction Underlying Early Onset Preeclampsia with Growth Retardation. J Pregnancy 2011: 521826. doi:10.1155/2011/521826. 
43. Abel DV, Abdul-Hamid O, Dijk MV, Oudejans CBM (2012) Transcription factor STOX1A promotes mitotic entry by binding to the CGNB1 promotor. PLoS ONE 7: e29769. doi:10.1371/journal.pone.0029769.

44. Kulkarni BB, Tighe PJ, Mohammed I, Yeung AM, Powe DG, et al. (2010) Comparative transcriptional profiling of the limbal epithelial crypt demonstrates its putative stem cell niche characteristics. BMC Genomics 11: 526. doi:10.1186/1471-2164-11-526.

45. Zhou M (2006) Transcriptional Profiling of Enriched Populations of Stem Cells Versus Transient Amplifying Cells: A COMPARISON OF LIMBAL AND CORNEAL EPITHELIAL BASAL CELLS. Journal of Biological Chemistry 281: 19600-19609. doi:10.1074/jbc.M600777200.

46. Akinci MAM, Turner H, Taveras M, Wolosin JM (2009) Differential Gene Expression in the Pig Limbal Side Population: Implications for Stem Cell Cycling, Replication, and Survival. Invest Ophthalmol Vis Sci 50: 5630-5638. doi:10.1167/iovs.09-3791.

47. Bian F, Liu W, Yoon K-C, Lu R, Zhou N, et al. (2010) Molecular signatures and biological pathway profiles of human corneal epithelial progenitor cells. Int J Biochem Cell Biol 42: 1142-1153. doi:10.1016/j.biocel.2010.03.022.

48. Romano AC, Espana EM, Yoo SH, Budak MT, Wolosin JM, et al. (2003) Different cell sizes in human limbal and central corneal basal epithelia measured by confocal microscopy and flow cytometry. 44: 5125-5129.

49. Spruessel A, Steimann G, Jung M, Lee SA, Carr T, et al. (2004) Tissue ischemia time affects gene and protein expression patterns within minutes following surgical tumor excision. BioTechniques 36: 1030-1037.

50. Ambati BK, Nozaki M, Singh N, Takeda A, Jani PD, et al. (2006) Corneal avascularity is due to soluble VEGF receptor-1. Nature 443: 993-997. doi: $10.1038 /$ nature 05249 .

51. Blanpain C, Horsley V, Fuchs E (2007) Epithelial stem cells: turning over new leaves. Cell 128: 445-458. doi:10.1016/j.cell.2007.01.014.

52. Adameyko I, Lallemend F, Aquino JB, Pereira JA, Topilko P, et al. (2009) Schwann cell precursors from nerve innervation are a cellular origin of melanocytes in skin. Cell 139: 366-379. doi:10.1016/j.cell.2009.07.049.

53. Ueno H, Ferrari G, Hattori T, Saban DR, Katikireddy KR, et al. (2012) Dependence of corneal stem/progenitor cells on ocular surface innervation. Invest Ophthalmol Vis Sci 53: 867-872. doi:10.1167/iovs.11-8438.

54. Deng SX, Sejpal KD, Tang Q Aldave AJ, Lee OL, et al. (2012) Characterization of limbal stem cell deficiency by in vivo laser scanning confocal microscopy: a microstructural approach. Arch Ophthalmol 130: 440445. doi:10.1001/archophthalmol.2011.378.

55. Watt FM, Jensen KB (2009) Epidermal stem cell diversity and quiescence. EMBO Mol Med 1: 260-267. doi:10.1002/emmm.200900033.

56. Jensen KB, Watt FM (2006) Single-cell expression profiling of human epidermal stem and transit-amplifying cells: Lrig1 is a regulator of stem cell quiescence. Proc Natl Acad Sci USA 103: 11958-11963. doi:10.1073/pnas.0601886103.

57. Jensen KB, Collins CA, Nascimento E, Tan DW, Frye M, et al. (2009) Lrigl expression defines a distinct multipotent stem cell population in mammalian epidermis. Cell Stem Cell 4: 427-439. doi:10.1016/j.stem.2009.04.014.

58. Wong VWY, Stange DE, Page ME, Buczacki S, Wabik A, et al. (2012) Lrigl controls intestinal stem-cell homeostasis by negative regulation of ErbB signalling. Nat Cell Biol 14: 401-408. doi:10.1038/ncb2464.

59. Prasad SM, Czepiel M, Cetinkaya C, Smigielska K, Weli SC, et al. (2009) Continuous hypoxic culturing maintains activation of Notch and allows longterm propagation of human embryonic stem cells without spontaneous differentiation. Cell Prolif 42: 63-74. doi:10.1111/j.1365-2184.2008.00571.x.
60. Zachar V, Prasad SM, Weli SC, Gabrielsen A, Petersen K, et al. (2010) The effect of human embryonic stem cells (hESCs) long-term normoxic and hypoxic cultures on the maintenance of pluripotency. In Vitro CellDevBiol-Animal 46: 276-283. doi:10.1007/s11626-010-9305-3.

61. Zachar V, Duroux M, Emmersen J, Rasmussen JG, Pennisi CP, et al. (2011) Hypoxia and adipose-derived stem cell-based tissue regeneration and engineering. Expert Opin Biol Ther 11: 775-786. doi:10.1517/14712598.2011.570258.

62. Ardehali R, Inlay MA, Ali SR, Tang C, Drukker M, et al. (2011) Overexpression of BCL2 enhances survival of human embryonic stem cells during stress and obviates the requirement for serum factors. Proceedings of the National Academy of Sciences 108: 3282-3287. doi:10.1073/pnas.1019047108.

63. Selver OB, Barash A, Ahmed M, Wolosin JM (2011) ABCG2-Dependent Dye Exclusion Activity and Clonal Potential in Epithelial Cells Continuously Growing for 1 Month from Limbal Explants. Invest Ophthalmol Vis Sci 52: 4330-4337. doi:10.1167/iovs.10-5897.

64. Pellegrini G (2001) p63 identifies keratinocyte stem cells. Proceedings of the National Academy of Sciences 98: 3156-3161. doi:10.1073/pnas.061032098.

65. Di Iorio E (2005) Isoforms of Np63 and the migration of ocular limbal cells in human corneal regeneration. Proceedings of the National Academy of Sciences 102: 9523-9528. doi:10.1073/pnas.0503437102.

66. Kasper M, Moll R, Stosiek P, Karsten U (1988) Patterns of cytokeratin and vimentin expression in the human eye. Histochemistry 89: 369-377.

67. Lauweryns B, van den Oord JJ, De Vos R, Missotten L (1993) A new epithelial cell type in the human cornea. Invest Ophthalmol Vis Sci 34: 1983-1990.

68. Shanmuganathan VA, Foster T, Kulkarni BB, Hopkinson A, Gray T, et al. (2007) Morphological characteristics of the limbal epithelial crypt. British Journal of Ophthalmology 91: 514-519. doi:10.1136/bjo.2006.102640.

69. Schermer A (1986) Differentiation-related expression of a major 64K corneal keratin in vivo and in culture suggests limbal location of corneal epithelial stem cells. J Cell Biol 103: 49-62. doi:10.1083/jcb.103.1.49.

70. Donisi PM, Rama P, Fasolo A, Ponzin D (2003) Analysis of limbal stem cell deficiency by corneal impression cytology. Cornea 22: 533-538.

71. Elder MJ, Hiscott P, Dart JK (1997) Intermediate filament expression by normal and diseased human corneal epithelium. Hum Pathol 28: 1348-1354.

72. Michel M, Török N, Godbout MJ, Lussier M, Gaudreau P, et al. (1996) Keratin 19 as a biochemical marker of skin stem cells in vivo and in vitro: keratin 19 expressing cells are differentially localized in function of anatomic sites, and their number varies with donor age and culture stage. J Cell Sci 109 (Pt 5): 1017 1028.

73. Larouche D, Tong X, Fradette J, Coulombe PA, Germain L (2008) Vibrissa hair bulge houses two populations of skin epithelial stem cells distinct by their keratin profile. The FASEB Journal 22: 1404-1415. doi:10.1096/fj.07-8109com.

74. Akinci MAM, Turner H, Taveras M, Barash A, Wang Z, et al. (2009) Molecular Profiling of Conjunctival Epithelial Side-Population Stem Cells: Atypical Cell Surface Markers and Sources of a Slow-Cycling Phenotype. Invest Ophthalmol Vis Sci 50: 4162-4172. doi:10.1167/iovs.08-2861.

75. Albert R, Veréb Z, Csomós K, Moe MC, Johnsen EO, et al. (2012) Cultivation and characterization of cornea limbal epithelial stem cells on lens capsule in animal material-free medium. PLoS ONE 7: e47187. doi:10.1371/journal.pone.0047187.

76. Kim H-S, Jun Song X, de Paiva CS, Chen Z, Pflugfelder SC, et al. (2004) Phenotypic characterization of human corneal epithelial cells expanded ex vivo from limbal explant and single cell cultures. Exp Eye Res 79: 41-49. doi:10.1016/j.exer.2004.02.015. 